\title{
The End of the Experiment: How ICANN's Foray into Global Internet Democracy Failed
}

\section{Citation}

John Palfrey. 2004. The end of the experiment: How ICANN's foray into global internet democracy failed. Harvard Journal of Law \& Technology 17(2): 409-473.

\section{Published Version}

http://jolt.law.harvard.edu/articles/pdf/v17/17HarvJLTech409.pdf

\section{Permanent link}

http://nrs.harvard.edu/urn-3:HUL.InstRepos:2643642

\section{Terms of Use}

This article was downloaded from Harvard University's DASH repository, and is made available under the terms and conditions applicable to Other Posted Material, as set forth at http:// nrs.harvard.edu/urn-3:HUL.InstRepos:dash.current.terms-of-use\#LAA

\section{Share Your Story}

The Harvard community has made this article openly available.

Please share how this access benefits you. Submit a story.

Accessibility 
Harvard Journal of Law \& Technology

Volume 17, Number 2 Spring 2004

\title{
THE END OF THE EXPERIMENT: HOW ICANN'S FORAY INTO GLOBAL INTERNET DEMOCRACY FAILED
}

\author{
John Palfrey*
}

TABLE OF CONTENTS

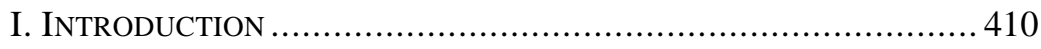

II. ICANN's HistORY, STRUCTURE, AND IMPORTANCE ............... 418

A. History and Principles.................................................. 418

B. ICANN's Hybrid Structure and Its Drain on Legitimacy........ 425

1. ICANN as a Standards Body........................................ 426

2. ICANN as a Corporation .......................................... 427

3. ICANN as a Government Entity ...................................... 429

C. Does ICANN Need Legitimacy: Does It Matter Whether

ICANN Lives Up to Its Principles?.................................. 432

III. THE FAILURE OF THE EXPERIMENT IN LEGITIMACY

THROUGH OPENNESS .................................................. 437

A. Confusion about "Openness" ......................................... 437

B. The Limits of Public Input in Decision Making at

ICANN

IV. THE FAILURE OF ICANN's EXPERIMENT IN

REPRESENTATION

A. The Election of 2000 ................................................. 446

B. Why ICANN's Semidemocratic Structure Was Doomed

to Fail......

1. ICANN as a Semidemocracy ...................................... 450

\footnotetext{
* John Palfrey is Executive Director of the Berkman Center for Internet \& Society at Harvard Law School and is a Lecturer on Law at Harvard Law School. A much earlier version of this paper was submitted in partial fulfillment of the requirements for the J.D. degree at Harvard Law School. The author also drew inspiration in part from an earlier paper entitled [names] alt-ICANN: The Technologies, Politics, and Structure of Control(on file with author), which was written in concert with Keith Abrams, Enoch Chang, and Jake Erhard for "Internet and Society 1999: The Technologies and Politics of Control," a class taught by Professor Jonathan Zittrain. The author is deeply indebted to Professor Zittrain, who has provided enormous guidance throughout the development of this paper. Also, the author owes a debt of grat itude for the research assistance of Noah Eisenkraft, Clifford Chen, Sam Hwang, and Jonathan Blavin, as well as the thoughtful advice of Andrew McLaughlin, Benjamin Edelman, and Diane Cabell. The author alone is responsible for all errors and omissions.
} 
2. Problems Facing ICANN as a Semidemocracy..... 454

a. The First-Tier Concern: Capture Without Recourse ........ 454

b. Second-Tier Concerns.................................................. 456

i. Cost and Inefficiency............................................ 457

ii. Less Effective Reaction to Change .......................... 457

iii. Danger of Nepotistic, Rather Than Meritocratic,

Promotion............................................. 458

iv. Transitions Are Handled Clumsily .......................... 459

C. The Semidemocratic Structure Does Nothing to Address

ICANN's Legitimacy of Authority Problem........................ 460

V. CONCLUSION ............................................................... 465

A. ICANN Should Pursue Meaningful Structural Reform........... 466

B. ICANN Should Clarify Its Governing Principles and

Ensure that Users Know How Best to Participate and

How, If at All, They Will Be Heard.

C. We Ought to Turn Our Focus Away from ICANN and

Toward Developing a Compelling Model for

Governance of the Technical Architecture of the

Internet.

\section{INTRODUCTION}

The Internet Corporation for Assigned Names and Numbers ("ICANN") has failed with its experiment in novel forms of governance and representation of the global Internet user community. ${ }^{1}$ However, ICANN will, at the very least, warrant a footnote in the history books. Its inception in the late 1990s as the Internet morphed from a limited network of academics, technologists, civil servants, and other trailblazers into a widely used and incessantly discussed global phenomenon placed ICANN in an intriguing role. At a fascinating moment in history, ICANN's mandate to coordinate a key aspect of the Internet's operations made it the first substantial Internet institution with a global reach. ${ }^{2}$ ICANN may also be worth chronicling as a sui generis institution that was at once obscure and a lightning rod for attention and criticism ${ }^{3}$ from government entities, legal scholars, and

1. See, e.g., David J. Farber et al., Overcoming ICANN: Forging Better Paths for the Internet (Mar. 18, 2002), at http://www.pfir.org/statements/icann (describing ICANN as a "failed experiment"). This notion of the failure of ICANN's experiment in "democratizing" its decision-making process is well described. See, e.g., Dan Hunter, ICANN and the Concept of Democratic Deficit, 36 LOY. L.A.L. REV. 1149 (2003).

2. See, e.g., David Post, Cyberspace's Constitutional Moment THE AMERICAN LAWYER Nov. 1998, at 117, available at http://www.temple.edu/lawschool/dpost/ DNSGovernance.htm.

3. Concern about the ICANN structure began even before ICANN got started in earnest. See Letter from J. Beckwith Burr, Associate Administrator of National Telecommunications \& Information Administration for International Affairs, to Dr. Herb Schorr, Executive Di- 
Internet users. These parties and many others have struggled with the questions of who should govern the technical architecture of the Internet, and how to do so legitimately. ${ }^{4}$ If the 2003 reform process continues on its desultory path, or if time runs out on ICANN's extension of its Memorandum of Understanding ("MoU") with the US. Department of Commerce, ICANN may well be remembered as a case study in organizational self-destruction. ${ }^{5}$

ICANN's ambitious experiment was to create its own legitimacy by harnessing the power of the Internet's potential for openness and representation. From the perspective of some stakeholders and onlookers, ICANN's central mission was to use the technologies, power, and attractiveness of the Internet ${ }^{6}$ to experiment in democratic

rector, USC Information Services Institute (Oct. 20, 1998), at http://www.ntia.doc.gov/ ntiahome/press/icann102098.htm ("[T] $]$ he public comments received on the ICANN submission reflect significant concems about substantive and operational aspects of ICANN.").

4. See Jonathan Weinberg, ICANN and the Problem of Legitimacy, 50 DUKE L.J. 187 (2000).

5. ICANN's woes, circa 2004, are legion. A series of nations, including Brazil, India, South Africa, China, and Saudi Arabia "are growing dissatisfied with the workings of California-based ICANN" and have pushed for the intervention of the U.N. in the Internet governance process. Frances Williams, Plan for UN to Run Internet "Will be Shelved," FIN. TIMES, Nov. 9, 2003. Aside from this collateral attack by several governments on ICANN and the perpetual dispute over representation, a distributed denial-of-service attack on October 21, 2002, in which seven of the thirteen DNS root servers were cut off from the rest of the Internet, raised questions about ICANN's fitness to carry out its core mission (which has ordinarily not been a major source of controversy ). See Richard Korman, Karl Aurbach: "ICANN Out of Control," O'REILly NETWORK (Dec. 5, 2002), at http://www.oreillynet.com/pub/a/policy/2002/12/05/karl.html. The U.S. General Accounting Office issued a report in Fall 2002, critical of ICANN's steps toward greater security protections for the root servers. See Hearing on ICANN Governance: Hearing before the Subcomm. on Sci., Tech., \& Space of the Senate Comm. on Commerce, Transp., \& Sci., 107th Cong. (2002) (statement of Peter Guerro, Director, Physical Infrastructure Group, General Accounting Office), available at http://www.gao.gov/new.items/d02805t.pdf. In addition, the departures of key ICANN staff in recent years, in particular CEO Stuart Lynn and Chief Policy Officer Andrew McLaughlin, have led to a great deal of crit icism. See, e.g., Patrick Thibodeau, Future of ICANN Remains Uncertain, COMPUTERWORLD (June 17, 2002), at http://www.computerworld.com/governmenttopics/government/policy/story/0,10801,72034, 00.html. But see Memorandum of Understanding Between the U.S. Department of Commerce and the Internet Corporation for Assigned Names and Numbers (Sept. 17, 2002) [hereinafter MoU 2002], available at http://www.icann.org/general/amend5 jpamou-19sep02.htm (extending by one year the agreement bet ween ICANN and the U.S. Department of Commerce); Statement of Department of Commerce Regarding Extension of Memorandum of Understanding with the Internet Corporation for Assigned Names and Numbers [hereinafter Statement Regarding MoU], at http://www.ntia.doc.gov/ ntiahome/domainname/agreements/sepstatement_09162003.htm (last visited Feb. 15, 2004) (stating reasons for extension).

6. See, e.g., ANDREW L. SHAPIRO, THE CONTROL REVOLUTION: HOW THE INTERNET IS PUTTING INDIVIDUALS IN CHARGE AND CHANGING THE WORLD WE KNOW 57-59 (1999) (discussing the Internet's potential to play a role in disintermediat ing politics); Alinta Thornton, Does Internet Create Democracy? (unpublished M.A. thesis, University of Technology, Sydney) (2002), at http://www.zip.com.au/ athornto; Mark Poster, CyberDemocracy: Internet and the Public Sphere (1995), at http://www.humanities.uci.edu/mposter/ writings/democ.html; Power to the People, ECONOMIST, Jan. 23, 2003, at 17, available at http://www.economist.com/surveys/displayStory.cfm?story_id=1534259 (describing the 
governance on a global scale. ${ }^{7}$ It sought to empower the Internet user community, including the private sector, to manage a system necessary for the stable operation of the Internet. ${ }^{8}$ Its novel, though ultimately flawed, structure has enabled a coalition of private-sector interest groups to manage the domain name system ("DNS") with broad input from individual users and limited but growing input from nation states. ${ }^{9}$ However, ICANN has failed to attract and incorporate sufficient public involvement to serve as the blueprint for building legitimacy through the Internet. Those who sought through ICANN to prove a point about Internet and democracy have misplaced their emphasis, because ICANN's narrow technical mandate has not lent itself to broad-based public involvement in the decision-making process.

Since its formation, ICANN has faced an uphill battle to establish the legitimacy of its authority. ${ }^{10}$ Its experimental decision-making structure grows out of its brief, unusual history and from the traditions of informal technical standards-setting bodies. Established by a few individuals, a few private standards bodies, several corporations, and the U.S. Department of Commerce, ICANN was founded in 1998 as a not-for-profit corporation based in California, USA. ${ }^{11}$ ICANN has sought to legitimate itself as an open and representative body, striving toward a bottom-up decision-making process grounded in consensus

expectations that the Internet would transform politics, and the disappointment in the reality that has ensued); COMMON CAUSE \& THE CTR. FOR DEMOCRACY \& TECH., ICANN'S GLOBAL ElECtions: ON THE INTERNET, FOR THE INTERNET (Mar. 2000), at http://www.commoncause.org/icann/introduction.htm\#1.1. But see CASS SUNSTEIN, REPUBLIC.COM (2001). These writings do not necessarily focus on ICANN, but rather on the broader argument regarding the role of information and communications technologies in strengthening or weakening democratic institutions.

7. There is substantial debate as to whether ICANN is in fact engaged in "governance" or in something else. There is a related debate as to whether ICANN makes "policy." See infra note 113 and accompanying text.

8. See, for example, the departing statement of ICANN board member Masanobu Katoh, who said that ICANN's participants should believe that ICANN can be a twenty-first century model for international organizations dealing with technology and new economy. Thomas Roessler, Carthage: A Good Board Meeting (Oct. 31, 2003), at http://log.does-notexist.org/archives/2003/10/31/929_carthage_a_good_board_meeting.html.

9. See, e.g., Kenneth N. Cukier, Why the Internet Must Regulate Itself, FIN. TIMES, Oct. 31, 2003, at 13, available at http://www.cukier.com/writings/FToct03.html (observing that ICANN has enabled community-driven self-regulation and describing the importance of such a concept).

10. See Weinberg, supra note 4, at 187 ("If ICANN is to establish its legitimacy, it must be able to answer the charge that its exercise of authority is inconsistent with our ordinary understandings about public power and public policymaking."). Professor Weinberg's art icle in some respects is what prompted the close data analysis involved in developing this Article. He posits that ICANN functions like an administrative agency, but without the backstop of judicial review when the agency's decisions go awry. Our review of how the board took account of user input focuses primarily on the period after publication of Professor Weinberg's piece, and largely supports his theory.

11. ARTICLES OF INCORPORATION OF INTERNET CORPORATION FOR ASSIGNED NAMES AND NUMBERS (revised Nov. 21, 1998) [hereinafter ARTICLES OF INCORPORATION], available at http://www.icann.org/general/articles.htm. 
and inclusion. ${ }^{12}$ The corporation was charged with the seemingly limited role of technical coordination of the Internet for the benefit of the Internet community as a whole. ${ }^{13}$ To carry out this mandate, ICANN has involved hundreds of thousands of people around the world, much in the same manner as its predecessor organizations did. ${ }^{14}$ Also, in the fall of 2000, ICANN held a global, Internet-based election to elect five of its nineteen directors. ${ }^{15}$ However, since that time, a committee of ICANN participants, as well as other outside observers who have conducted major studies of that election, have questioned how the organization's membership should participate in ICANN's business. ${ }^{16}$ Likewise, the former CEO and President of ICANN, M. Stuart Lynn, pursued radical reform of ICANN's structure in an attempt to recapture ICANN's legitimacy. ${ }^{17}$

ICANN has offered a wide range of ways in which members of the Internet user community may participate in the organization's decision-making process, ${ }^{18}$ but the extent to which ICANN paid attention to that user participation is much less clear. Throughout ICANN's history, users have had the ability to post public commentary about general or specific issues before the ICANN board. ${ }^{19}$ Users may attend or participate remotely in public meetings at which the board,

12. ICANN, Fact Sheet, at http://www.icann.org/general/fact -sheet.html (last visited Feb. 15, 2004).

13. Id.

14. To a substantial extent, ICANN can be seen as an outgrowth of several volunteerdriven standards bodies. Professor Michael Froomkin and others have extensively examined the connections between ICANN and other pre-existing organizations with Internet standards development or management mandates. See infra note 33 and accompanying text.

15. ICANN, About ICANN's At Large Membership Program, at http://members.icann.org/about_at_large.htm (last visited Feb. 15, 2004).

16. See NGO \& ACADEMIC ICANN STUDY, ICANN, LEGITIMACY, AND THE PUBLIC VOICE: MAKING GLOBAL PARTICIPATION AND REPRESENTATION WORK (Aug. 31, 2001), at http://www.naisproject.org/report/final/execsummaryUSLetter.pdf; At-LARGE STUDY COMMITTEE, FINAL REPORT ON ICANN AT LARGE MEMBERSHIP (Nov. 5, 2001), at http://www.atlargestudy.org/final_report.shtml. The NGO and Academic ICANN Study is made up of the collective views of a wide range of parties outside the ICANN structure. The At-Large Study Committee, a broad-based group of persons active in the ICANN process, prepared a report to the ICANN board. Both studies reviewed the election process and the future of the At-Large Membership and recommended revised structures for ICANN, though both would have perpetuated some form of a semidemocratic structure. For a comparison of the two studies, see John Palfrey, Comparisons of At Large Study Commitee (ALSC) and NGO and Academic ICANN Study (NAIS) Reports (Sept. 2001), at http://cyber.law.harvard.edu/people/palfrey/ALSC-NAIS-comparison.

17. Press Release, ICANN, ICANN President Recommends a Roadmap for Reform (Feb. 24, 2002), at http://www.icann.org/announcements/announcement-24feb02.htm.

18. See, e.g., ICANN, Participate in ICANN, at http://www.icann.org/participate (last modified Dec. 5, 2003). In addition to formal involvement in ICANN's decision-making process, those interested in the outcome of its decisions have created a variety of watchdog organizations, such as ICANNWatch (www.icannwatch.org), ICANNFocus (www.icannfocus.org), and others.

19. See ICANN Public Comment Forum, at http://forum.icann.org (last visited Feb. 15, 2004). 
staff, and other entities make decisions. ${ }^{20}$ Also, users may volunteer for a variety of tasks, most notably through participation in the Supporting Organizations and Advisory Committees. Recently, the AtLarge Advisory Committee has played a central role in facilitating involvement of the user community. ${ }^{21}$

While thousands of users since ICANN's founding have sought to participate through these means, it ppears as though this extensive participation has affected few important decisions. ${ }^{22}$ The reason for this is that the structure ICANN adopted to fulfill its charter is so complex and obscure that too few people have been able to figure out how to contribute meaningfully. ${ }^{23}$ It is so complex, in fact, that there are few useful analogs. ${ }^{24}$ From a legal perspective, ICANN is a corporation, governed by its own charter and by-laws, and the laws of the State of California. ${ }^{25}$ From an historical perspective, ICANN has attributes in common with a standards body: a volunteer-driven effort that joins corporate interests, academics, and interested people in their individual capacities from around the world. ${ }^{26}$ From a functional perspective, though, ICANN has elements of a government entity: an association of people joined by a compact to make decisions about a particular process or series of interests. ${ }^{27}$ The Election of 2000 strengthens the parallel between ICANN and a governmental form, particularly what political scientists call a "semidemocracy."

20. See ICANN Meeting Schedule, at http://www.icann.org/meetings/ (last modified Dec. 5, 2003).

21. See ICANN At-Large Advisory Committee, at http://alac.icann.org/ (last visited Feb. $15,2004)$.

22. See infra Section III.B.

23. See Lawrence R. Helfer \& Graeme B. Dinwoodie, Designing Non-National Systems: The Case of the Uniform Domain Name Dispute Resolution Policy, 43 WM. \& MARY L. REV. 141, 178 (2001) (describing the ICANN structure as "Byzantine"); see also ICANN, Organizational Chart, at http://www.icann.org/general/icann-org-chart.htm (last modified Jan. 12, 2004).

24. But see, e.g., Milton MUELLER, RULING THE ROOT: INTERNET GOVERNANCE AND THE TAMING OF CYBERSPACE 217-18 (2002) (arguing that while analogies are hard to draw, the best comparison is to the radio frequency administration at the national level).

25. See ARTICLES OF INCORPORATION, supra note 11; ICANN BYLAWS (last amended Oct. 13, 2003), available at $\mathrm{http}: / / \mathrm{www}$.icann.org/general/bylaws.htm.

26. Many of the key ICANN participants, including the board of directors, serve without pay. Longtime Chairman of the Board Vinton Cerf, among others, pays his own expenses to attend the quarterly meetings around the world.

27. This issue, and others discussed in this paper, is debated at length in the back-andforth writings of Joe Sims, ICANN's counsel and a partner at Jones Day, and his co-author Cynthia L. Bauerly, on the one hand, and Professor A. Michael Froomkin on the other. See generally A. Michael Froomkin, Wrong Turn in Cyberspace: Using ICANN to Route Around the APA and the Constitution, 50 DUKE L.J. 17 (2000); Joe Sims \& Cynthia L. Bauerly, A Response to Professor Froomkin: Why ICANN Does Not Violate the APA or the Constitution, 6 J. SMALl \& EMERGING BUS. L. 65 (2002); A. Michael Froomkin, Form and Substance in Cyberspace, 6 J. SMALl \& EMERGING Bus. L. 93 (2002); Joe Sims \& Cynthia L. Bauerly, A Reply to Professor Froomkin's Form and Substance in Cyberspace, $6 \mathrm{~J}$. SMALL \& EMERGING BUS. L. 125 (2002); Weinberg, supra note4; see also MUELLER, supra note 24 , at 218 . 
ICANN has elements of all three structural forms, but no single element dominates. This hybrid organizational form is a historical accident rather than the result of clear, principled planning from the outset. Would-be participants, and even academics with a lot of time on their hands, must work hard to understand the decision-making process. This complexity is a problem in itself, because it serves as a stumbling block to ICANN's goal of broad public partic ipation. If ICANN genuinely seeks to gain legitimacy of authority through openness, the public must know how to participate so they can be heard.

In addition to the relatively ad hoc means of user participation, ICANN held an online global election in the fall of $2000 .^{28}$ This election was the most ambitious of its several attempts to engage the world's Internet users in a common, open, democratic process. ${ }^{29}$ Despite severely limited resources, ICANN's election enfranchised voters from every region of the world. More than 76,000 people registered to vote at the Internet polling booths set up by Election.com to elect five ICANN directors. ${ }^{30}$

The relative tactical success of this election is overshadowed by the overall failure of ICANN's experiment in at-large representation and participation. The story of formal representation through public elections of ICANN's board effectively drew to a close on December 15,2002 , as the elected directors' terms ended, and the by-laws changed to end the experiment. ${ }^{31}$ The shortcomings of this single experiment, which can be traced in large measure to a lack of widespread interest in the institution's highly technical mandate and a futile attempt to establish an unsustainable semidemocracy, should not stand for the proposition that Internet-based elections, activist movements, or global democratic institutions, cannot or will not emerge. ${ }^{32}$ However, it does suggest that ICANN is not the organization to prove this point.

The outlook for ICANN's experiment in broad-based, global representation is very dim. ${ }^{33}$ ICANN's leadership maintains that it is "en-

28. See Press Release, ICANN, ICANN Selects Election.com to Conduct One of World's Largest All-Internet Votes (Sept. 21, 2000), at http://www.icann.org/announcements/icannpr21sep00.htm.

29. See Oscar S. Cisneros, ICANN Elections Under Way, WIRED.COM (Oct. 2, 2000), at http://www.wired.com/news/politics/0,1283,39130,00.html.

30. See Press Release, At-Large Member Committee, Carter Center Representatives Observe ICANN Balloting (Oct. 11, 2000), at http://members.icann.org/carter.htm.

31. See ICANN BYLAwS (effective Dec. 15, 2002), available at http://www.icann.org/ general/archive-bylaws/bylaws-15dec02.htm. The existing At-Large directors remain on the "transition board" until the next election under the reformed procedures.

32. See Computer Prof'ls for Social Responsibility, Registration of Internet Domain Names, at http://www.cpsr.org/cpsr/nii/cyber-rights/web/current-domain.html (last updated Nov. 21, 2000) (referring to ICANN as a "semi-democracy").

33. See A. Michael Froomkin, Habermas @ discourse.net: Toward a Critical Theory of Cyberspace, 116 HARV. L. REV. 749, 838-55 (2003). Professor Froomkin's article is surely the most ambitious paper written about the decision-making structure of ICANN and one of 
couraging other forms of at-large organizations to self-organize and create and encourage a body of individuals who could provide the user input and public interest input into the ICANN process. ${ }^{34}$ However, hope has been further lessened by the continued calls to review ICANN's structure and mission from members of the U.S. Congress, such as Senator Conrad Burns (R-MT) and Congressman Edward Markey (D-MA), and leaders in non-governmental organizations, such as Zoë Baird, President of the Markle Foundation. ${ }^{35}$ It seems certain, however, that if ICANN is not changed radically, the tension between ICANN's efforts to make itself representative and its complex institutional structure - particularly its corporate form - will continue to create problems over time. ${ }^{36}$

This Article explores ICANN's struggle with legitimacy of athority. ICANN's experiment in legitimacy was actually two interrelated experiments: to use the Internet to create legitimacy through openness, and to create legitimacy through representation. The experiment in openness failed because openness requires clarity, and ICANN's hybrid organizational form has only obscured how decisions are made. When the experiment in openness failed, ICANN tried to salvage its legitimacy through representation in the Election of 2000. However, this too failed because it made ICANN into a semidemocracy. To escape its current crisis of legit imacy, ICANN has to discard half measures and become either truly open and truly representative, or abandon such distractions and focus on succeeding in its narrow tec hnical mandate.

This Article argues that ICANN should relinquish responsibility for the experiment, because its highly technical mandate rendered

the more comprehensive considerations of where ICANN fits in the discussion of govemance on the Internet. Among numerous arguments, Professor Froomkin contends that the ICANN model, in light of Jurgen Habermas's standard for discourse ethics, pales in comparison to the Internet Engineering Task Force ("IETF") model. Professor Froomkin's tour de force regarding standards-making in the Internet space and his use of Habermas's discourse theory of law is an important contribution to the field of Internet governance. Habermas's theory, and Froomkin's application thereof, has certain attractive elements, particularly with regard to the communicative power of discourse in influencing administrative decisions and the impact that power has on how organizations responsible for Internet standards-making should be organized. I disagree with Professor Froomkin with respect to some of his ultimate findings about the Internet and democracy, particularly in the manner in which he compares the IETF and ICANN models, yet I am indebted to him for the depth of his research, the seriousness of his inquiry, and the explicit links he draws to Habermas's thinking.

34. Posting of M. Stuart Lynn, President and CEO of ICANN, to India Chennai, at http://www.washingtonpost.com/wp-srv/technology/transcripts/archive_icann_062002.htm (last visited June 20, 2003).

35. See, e.g., Joanna Glasner, Senators Weigh ICANN's Future, WIRED.COM (June 13, 2002), at http://www.wired.com/news/business/0,1367,53159,00.html.

36. See, e.g., Interview by Damien Cave with John Gilmore, ICANN Critic and Internet Pioneer (July 2, 2002), at http://www.salon.com/tech/feature/2002/07/02/gilmore/ index $2 . h t m l$ (describing the problems besetting ICANN in light of its present corporate structure). 
ICANN, as an institution, ill-suited to serve as the test bed for a new, user-driven model of decision making. As important as ICANN's mandate is, there are numerous technical aspects of the Internet that concern users more directly and substantially than the coordination of the DNS, as Professor Jonathan Zittrain has argued. ${ }^{37}$ The job of directing users to websites in response to the entry of search queries on the web - run almost exclusively by private parties such as Google, AltaVista, Overture, Microsoft, and others - has greater immediate relevance today to users than the port allocation managed by ICANN. Similarly, the exercise of authority by state actors and those they regulate, such as Internet Service Providers, to filter aspects of Internet traffic without warning ex ante or recourse ex post has far greater impact on what a user of the Internet experiences and what resources he or she can access through the network. ${ }^{38}$ An institution that would be able to succeed in the experiment by enabling the user community meaningfully and directly to be involved in the decision-making process would likely have a mandate of greater accessibility and significance to the Internet user community than ICANN's narrow mandate to coordinate the DNS.

We have yet to develop a compelling theory of governance for the technical architecture of the Internet. ${ }^{39} \mathrm{We}$ ought to consider ICANN's story in this broader context of Internet governance, considering the role not only of individuals but also of corporations and governments in the process of decision making regarding these issues of global and common importance. ${ }^{40}$

I begin ICANN's story in Section II by briefly reviewing the history of ICANN to illustrate how its founding principles and organizational structure conflict to drain legitimacy of authority from ICANN.

37. See Jonathan Zittrain, Address at the Cardozo Law School (Mar. 17, 2003), available at http://cyber.law.harvard.edu/icann/jzcardozo.html.

38. Professor Jonathan Zittrain and Benjamin Edelman have conducted multiple studies of Internet filtering by state actors and private sector entities. See JONATHAN ZITTRAIN \& BENJAMIN EDELMAN, DOCUMENTATION OF INTERNET FILTERING WORLDWIDE, at http://cyber.law.harvard.edu/filtering/ (last updated Oct. 24, 2003).

39. There are several very strong theories about who controls the Internet, though not a complete answer to the question about how we should govern the Internet's technical architecture. The definitive theory of control on the Internet is Professor Lawrence Lessig's description of architecture (or code), law, norms, and market in cyberspace. Professor Lessig has developed this theory in a number of written works and has presented iterations of this idea numerous times. See, e.g., LAWRENCE LESSIG, CODE AND OtHER LAWS OF CYBERSPACE (1999); see also Viktor Mayer-Schoenberger, The Shape of Governance: Analyzing the World of Internet Regulation, 43 VA. J. INT'L L. 605 (2003) (describing a "blended" model of governance); Steven R. Salbu, Who Should Govern the Internet? Monitoring and Supporting a New Frontier, 11 HARV. J.L. \& TECH. 429, 454 (1998) (giving one of the earliest, and most enduring, discussions of Internet governance). See generally ADAM ThIERER \& Clyde WAYNe CREWS, JR., EDS, Who RUles the NeT? INTERNET GOVERNANCE AND JURISDICTION (2003).

40. See Zittrain, supra note 37 (making the point that ICANN's story ought to be set in the broader context of Internet governance). 
In Section III, I argue that a fundamental confusion about the meaning of "openness," combined with ICANN's convoluted decision-making structure, caused the experiment in openness to fail, because users could not reasonably believe that the board listened to their concerns. Section IV argues that, in response to criticism generated by the failure of the experiment in openness, ICANN tried to achieve legitimacy through representation. However, his too failed because it made ICANN into a legitimacy-draining semidemocracy. In conclusion, I point to some of the implications of this short history for ICANN itself and for the study of how best to govern the technical architecture of the Internet.

\section{ICANN'S HISTORY, STRUCTURE, AND IMPORTANCE}

The history of ICANN, and the principles on which it was founded, help explain the structure of the institution, the struggle over the issue of representation, and how its problem of legitimacy came to be. ${ }^{41}$ The first principles on which ICANN was founded are the seeds of its fundamental problem: if its legitimacy was truly meant to come from the Internet user community through its founding principles of openness and representation, its history and structure set it up to fail on its own terms.

\section{A. History and Principles}

The story of ICANN's formation has been told, at least in part, by several scholars. ${ }^{42}$ The most critical part of this story is that the founders - a mix of academics, government officials, corporate executives, and technologists - agreed upon a set of principles that have proven to be mutually exclusive. Most difficult to reconcile is that the founders wanted a private sector corporation to operate in a manner that is "representative" of global interests and "open" in its management decision making. ${ }^{43}$ In striving for consensus, the foun-

41. See generally Weinberg, supra note 4.

42. The most thorough history of ICANN is probably MUELLER, supra note 24. For some others worth noting, see also Weinberg, supra note 4; Ctr. for Democracy and Tech., Domain Name Management Policy: ICANN Formation, at http://www.cdt.org/ dns/icann/formation.shtml (last visited Feb. 24, 2004); ICANN, History of ICANN At Large, at http://members.icann.org/history.html (last visited Feb. 24, 2004); Robert Zakon, Hobbes' Internet Timeline V.7.0, at http://www.zakon.org/robert/internet/timeline/ (last visited Feb. 24, 2004).

43. See, e.g., Domain Name System Privatization: Is ICANN Out of Control? Hearing before the House Subcomm. on Oversight \& Investigations of the U.S. House Comm. on Commerce, 106th Cong. 134-274 (1999) (statement of Jonathan Zittrain, Executive Director, The Berkman Center for Internet \& Society at Harvard Law School), available at $\mathrm{http} / / / \mathrm{com}$-notes.house.gov/cchear/hearings106.nsf/768df0faa6d9ddab852564f1004886c0/ 53d384d363224ef2852567b7005119bc?OpenDocument; see also Post, supra note 2 (re- 
ders may have set themselves up for failure by embarking on a mission that is impossible to achieve completely. ${ }^{44}$

To a certain extent, despite Professor Mueller's thorough history and related efforts, the development of ICANN's structure has remained shrouded in secrecy. ${ }^{45}$ The means by which many of the initial board members and officers were chosen is particularly unclear. Prior to ICANN, the technical coordination of key aspects of the Internet's infrastructure was handled on an essentially ad hoc basis by a number of individuals in loose-knit, consensus-driven standards bodies such as the Internet Engineering Task Force ("IETF"). ${ }^{46}$ ICANN's immediate predecessor, the Internet Assigned Numbers Authority ("IANA"), consisted essentially of Dr. Jon Postel of the University of Southern California and a very limited administrative staff. ${ }^{47}$ However, fter decades of management of the DNS, and as increasing numbers of people wanted access to the system and to the levers of control, the job became too large for these organizations. ${ }^{48}$ Disputes began to arise between these loose-knit organizations, the US. government, ${ }^{49}$ and private corporations such as Network Solutions, Inc., which had contracted to control the lucrative ".com" top-level domain. ${ }^{50}$

The reliance on a single nation's grant of authority lies near the core of ICANN's legitimacy problems. Despite its global mandate,

garding discussions of the goals of ICANN and their relevance to the governance of the instit ution).

44. Many political thinkers, from Locke to Jefferson, have talked about the problem of scale in the context of organizational form. On a smaller scale, a form of organization allo wing for a great deal of input is plausible. On a larger scale, living up to principles of representation and openness - as the representatives grow further away from those they represent - may be impossible to achieve. The global nature of ICANN sets the bar particularly high in this regard.

45. See Jonathan Zittrain, Book Review, What's in a Name?, 55 FED. COMM. L.J. 153, 158 (2003).

46. See Froomkin, supra note 33, 782-815. Professors Froomkin, Mueller, and others have done admirable jobs of retelling the story of the IETF and its transition into the ICANN era.

47. See IANA Public Comments and Archives, at http://www.iana.org/comments/ comments.htm (last visited Dec. 3, 2002).

48. In general, business law scholars suggest that larger groups of people with divergent interests and access to information require the delegat ion of authority to a few leaders, while smaller groups with better aligned interests and access to information tend to work better by consensus. See STEPHEN M. BAINBRIDGE, CORPORATION LAW AND ECONOMICS 192-94 (2002). I revisit this notion that organizations must decide between a "consensus" approach and an "authority" approach to self-governance in Section II.B.2.

49. The U.S. government's involvement was primarily through the National Science Foundation ("NSF") during the IANA period, and the Department of Commerce thereafter. It is an interesting question as to how the NSF or the Department of Commerce derived their initial authority over the domain name system. For one analysis of this topic, see Joseph P. Liu, Legitimacy and Authority in Internet Coordination: A Domain Name Case Study, 74 IND. L.J. 587, 593 (1999).

50. VeriSign, Inc., purchased Network Solutions, Inc. in 2000, but subsequently sold off all these assets in 2003. 
ICANN retains extremely close ties to only one nation, the United States. ${ }^{51}$ ICANN emerged from a U.S. government initiative, in concert with members of the private sector and the technical Internet community, intending to resolve the brewing dispute over governance of the DNS. ${ }^{52}$ The United States briefly considered taking over the DNS, but instead produced two preliminary documents in 1998, known as the "Green Paper" set forth a series of policy prescriptions and principles to govern how the DNS would be managed. At the most fundamental level, the Green and White Papers established that the US. government would not actively manage the domain name system, but would rather empower the private sector to lead. ${ }^{55}$

In the wake of these policy pronouncements, representatives of IANA negotiated an agreement with the US. Department of Commerce in November $1998 .{ }^{56}$ Based upon this agreement, ICANN came into being through the formation of a not-for-profit corporate entity in California. Its charter and by-laws incorporated a series of principles that reflected the desires of the founders as well as those of the Clinton Admin istration. ${ }^{57}$

Once formally established as a California corporation, ICANN's initial board and officers are believed to have been hand-picked largely by the late Dr. Postel (who died abruptly in October 1998) through his authority at IANA. ${ }^{58}$ In theory, the board membership was chosen to be representative of a cross-section of geographic areas ef-

51. Perhaps the most important documentation of this tie is the first Memorandum of Understanding. See Memorandum of Understanding Between ICANN and the United States Department of Commerce [hereinafter MoU 1998] (Nov. 25, 1999), available at http://www.ntia.doc.gov/ntiahome/domainname/icann.htm.

52. See id.

53. NAT'L Telecomm. \& InFo. Admin., A Proposal to Improve Technical MANAGEMENT OF INTERNET NAMES AND ADDRESSES (Jan. 30, 1998) [hereinafter GREEN PAPER], available at http://www.ntia.doc.gov/ntiahome/domainname/dnsdrft.htm.

54. NAT'L TELECOMM. \& INFO. ADMIN., MANAGEMENT OF INTERNET NAMES AND ADDRESSES (June 5, 1998) [hereinafter WHITE PAPER], available at http://www.ntia.doc.gov/ntiahome/domainname/6_5_98dns.htm.

55. See MUELLER supra note 24, at 1-10.

56. See generally MoU 1998, supra note 51.

57. The U.S. government's role in managing the DNS, which continues to this day, could profitably serve as the subject of its own inquiry. Non-U.S. critics have repeatedly brought up the involvement of the Department of Commerce in aspects of ICANN management, particularly in terms of involvement in the contracting process between ICANN and Network Solutions. A good archive of materials regarding the U.S. government's policies on Internet -related issues can be found at http://www.ecommerce.gov. ICANN has periodically gone through a contract extension process with the U.S. Department of Commerce, most recently extending the MoU through 2006. See, e.g., Statement Regarding MoU, supra note 5.

58. See ICANN't Believe What They're Doing, NAT'L J.'s TECH. DAILY (June 17, 1999), at http://cyber.law.harvard.edu/pil-99/icannt.txt; see also Milton Mueller, ICANN and Internet Governance: Sorting Through the Debris of "Self-Regulation," 1 INFO. 497, 498 (Dec. 1999). 
fected by the DNS. ${ }^{59}$ The initial board was made up of a number of highly respected members of the Internet community, including chairwoman Esther Dyson, an experienced US.-based entrepreneur, journalist, and a long-time leader in the technology world. ${ }^{60}$ The formal role and governing principles of ICANN, as well as an explanation of the source of ICANN's authority, are set forth clearly in the MoU between the U.S. Department of Commerce and ICANN. ${ }^{61}$ The MoU delineates a role for ICANN that is largely confined to managing technical DNS functions, the numbering of Internet addresses, the coordination of port assignments, and assisting in the maintenance of the stability of the Internet. ${ }^{62}$ ICANN was established to work with the U.S. Department of Commerce to ensure that the "private sector has the capability and resources to assume the important responsibilities related to the technical management of the DNS." ${ }^{13}$ The project listed the following among its goals: encouraging international participation, ${ }^{64}$ providing expertise and advice on the allocation of IP number blocks and coordinating the assignment of other Internet technical parameters as needed to maintain universal connectivity of the Internet, ${ }^{65}$ collaborating on written technical parameters for operation of the authoritative root, ${ }^{66}$ and collaborating on a study and proc-

59. This characterization of ICANN's development process almost dangerously oversimplifies the story. However, there is a dearth of reliable information about the process; the record is replete with conspiracy theories, but short on official statements or reasonably objective historical inquiries.

60. See ICANN, Esther Dyson, at http://www.icann.org/biog/dyson.htm (last visited Jan. 24, 2002).

61. MoU 1998, supra note 51.

62. The specific role set forth for ICANN, as compared with the work that the IETF seeks to accomplish, is a key reason for my disagreement with Professor Froomkin's assessment of standards-making bodies. See Froomkin, supra note 33. There is a substantial difference between what the IETF does in setting standards and what IANA and ICANN have sought to do in managing the DNS and related technical tasks. These disparate functions call for different modes of organization, structure, and discourse. This distinction is set forth nicely in a paper by Joseph Liu. Professor Liu, on the distinction between the proper mode for technical standards-setting and management of the DNS, wrote that proposals to extend IETF-style decision making processes to ICANN fail to:

[A]ppreciate the fact that domain name problems are not purely, or even primarily, technical in nature. Rather, they are classic public policy questions, requiring the resolution of conflicting distributional and value chains. The public policy aspect of the domain name problem undercuts many of the assumptions that underlie the standardsetting model of coordination. The result is that attempts to use the current standard-setting process face serious legitimacy and implementation problems.

Liu, supra note 49, at 589.

63. MoU 1998, supra note 51, arts. II.A-II.B.

64. See id. art. II.A.

65. See id. art. V.C.1.

66. See id. art. V.C.4. 
ess to address operational requirements of the root name servers and the security of the root server system. ${ }^{67}$

Most important for this inquiry, the MoU specifically set a goal for ICANN of achieving "representation" through process, as set forth in the following clause:

4. Representation. This Agreement promotes the technical management of the DNS in a manner that reflects the global and functional diversity of Internet users and their needs. This Agreement is intended to promote the design, development, and testing of mechanisms to solicit public input, both domestic and international, into a private-sector decision making process. These mechanisms will promote the flexibility needed to adapt to changes in the composition of the Internet user community and their needs. ${ }^{68}$

Those who initially conceived ICANN acknowledged the global nature of the network, the global implications of the technical management that they were undertaking, and the need to take into account the needs and composition of the Internet user community. In so doing, the founders of ICANN committed themselves to managing the organization in such a way as to achieve representation of a constituency arguably unparalleled in its breadth. ${ }^{69}$ The ICANN founders also established ICANN with a view toward testing new mechanisms for involving the public in a private-sector decision-making process. ICANN subsequently chartered a study on representation by the Berkman Center for Internet and Society at Harvard Law School and frequently requested comment by others on the topic of representation. ${ }^{70}$ The statement by the U.S. Department of Commerce on Sep-

67. See id. art. V.C.5(a). Many of these same principles can be found in the Green and White Papers. See GREEN PAPER, supra note 53; W HITEPAPER, supra note 54.

68. MoU 1998, supra note 51, art. II.C.4.

69. See Weinberg, supra note 4, at 235-50 (arguing that it is extremely difficult to determine whether ICANN's process is truly "representative" of a global community of users).

70. BERKMAN CTR. FOR INTERNET \& SOC'Y AT HARVARD LAW SCH., REPRESENTATION IN CYBERSPACE STUDY, at http://cyber.law.harvard.edu/rcs (last modified May 26, 1999); see, e.g., ICANN Public Meeting Transcript (Nov. 14, 1998), at http://cyber.law.harvard.edu/icann/cambridge-1198/Archive/transmembership.html Later, ICANN moved away from public involvement. See ICANN, Preliminary Report: ICANN Meeting in Accra (Mar. 14, 2002), at http://www.icann.org/minutes/ prelim-report-14mar02.htm (recounting statements of the ICANN leadership when abolishing direct representation at the meeting in Accra, Ghana); Andrew Orlowski, ICANN Abolishes Net Democracy, But Esther Steps In, THE REGISTER (Mar. 15, 2002), at http://www.theregister.co.uk/content/6/24443.html (criticizing both ICANN's decision to abolish direct representation and the subsequent gestures of former ICANN chair Ester Dyson). 
tember 16, 2003, regarding the extension of the MoU, reiterates the use of the word "representative" in multiple contexts. ${ }^{71}$

Despite - or perhaps because of - the articulation of this founding principle, much of the critique of ICANN to date has revolved around the problem of representation. ${ }^{72}$ Representation has proven problematic because of the extremely high expectations (set by the governing principles) that the organization's leaders would represent such enormous and varied constituencies and the lack of precision about what "representation" means. ${ }^{73}$ Critics of ICANN have been vocal, expressing their views through websites, bulletin boards, listservs, and the news media. ${ }^{74}$ Certain participants have concluded that corporate interests have been granted too much authority in the process. ${ }^{75}$ Similarly, some have argued that the process favors U.S. interests too greatly. ${ }^{76}$ Still others have accused the initial board of moving too slowly to become a more formally representative body. ${ }^{77}$ Few have argued that representation should not be a governing principle of the organization. My argument is, in essence, that if ICANN commits to holding itself out as representative of the Internet user community, ICANN should both clarify and make good on its commitment.

In addition to seeking to represent the global community of Internet users, the founders of ICANN committed to an "open" manner of managing the DNS and making decisions. Like the variety of possible meanings of "representation," a clash of several understandings of the meaning of "open" has also contributed to the hybrid nature of the ICANN structure. The notion of openness is often cited in the early writings about what makes cyberspace distinctive. Openness as a concept - as in "open source," "open access," or even "open law" — has taken on a nearly mythic status in cyberlaw writings. Longtime collaborators Professor Lawrence Lessig of Stanford Law School and

71. Statement Regarding MoU, supra note 5; see also MoU 2002, supra note 5 (reiterating the commitment to "representation").

72. See David R. Johnson \& Susan P. Crawford, Why Consensus Matters: The Theory Underlying ICANN's Mandate to Set Policy Standards for the Domain Name System, ICANN WATCH (Aug. 23, 2000), at http://www.icannwatch.org/archive/ why_consensus_matters.htm; David R. Johnson \& Susan P. Crawford, The Idea of ICANN, ICANN WATCH (Feb. 12, 2001), at http://www.icannwatch.org/archive/ the_idea_of_icann.htm.

73. See Weinberg, supra note 4, at 259-60.

74. The websites hosting a vast and growing archive of information critical of ICANN include official ICANN sites, such as www.icann.org, as well as www.icannwatch.org and www.slashdot.org. A simple search on Google (www.google.com), for instance, with the term "ICANN" yields many other sources of critical information. See also ICANN Blog Aggregator, at http://aggregator.does-not-exist.org (last visited Feb. 19, 2004).

75. See Gordon Cook, At War for the Future of the Internet, at http://cookreport.com/icannregulate.shtml(last visited Mar. 3, 2004).

76. See Jennifer Rast, The U.N. Plan to Take Over the Internet, CONTENDER MINISTRIES (Jan. 10, 2004), at http://www.contenderministries.org/UN/wsis.php.

77. See supra note 16. 
Professor Charles Nesson of Harvard Law School have written and spoken about the importance of the "open society" in cyberspace and the many threats to that ideal. ${ }^{78}$ The open society is held out as one manifestation of the great promise of the Internet as a digital commons in which empowerment of individuals, widespread sharing of ideas across cultural and other boundaries, and free expression are glorified. ${ }^{79}$ The idea of openness, with its many various connotations, has tremendous resonance and multiple special meanings to the activists of the Internet community.

Since the founding of ICANN, the officers and directors have continued to restate their commitment to representation and openness. ${ }^{80}$ At the very least, the managers have continued to employ the rhetoric of these founding principles. ${ }^{81}$ One sentence from the organization's public website bundles the principles together: "It is ICANN's objective to operate as an open, transparent, and consensus based body that is broadly representative of the diverse stakeholder communities of the global Internet." ${ }^{82}$ The recent leadership of ICANN has underscored this commitment to representation. M. Stuart Lynn, upon appointment as president and chief executive, said, "ICANN takes its lead not from me but from the Internet community as a whole. ${ }^{" 83}$ Based on this guidance, Mr. Lynn issued a statement one year later that the experiment that is ICANN should take a dra-

\footnotetext{
78. See, e.g., Lawrence Lessig, Reclaiming a Commons, Keynote Address at the Berkman Center's "Building a Digital Commons" (May 20, 1999), available at http://cyber.law.harvard.edu/events/lessigkeynote.pdf; see also Open Society Institute, at www.soros.org/about (last visited Feb. 7, 2004).

79. See generally LESSIG, supra note 39 (outlining the classic and most effective description of the promise, realities, and future of cyberspace, as told partway through the Internet explosion). See also Salbu, supra note 39.

80. For instance, ICANN President Paul Twomey is quoted as saying that ICANN is pursuing "a more open process" for creating new top-level domains. Ctr. for Regulatory Effectiveness, ICANN Pledges to Adopt Unspecified New Domain Name Selection Process, at http://thecre.com/icann/govern-oct2003-1.htm (last visited Feb. 23, 2004); see also James Pearce, New ICANN Head Promises Greater Openness, ZDNET UK (Mar. 20, 2003), at http://news.zdnet.co.uk/business/0,39020645,2132226,00.htm (quoting Twomey committing to an ICANN that is "very open and consultative with all the stakeholders."); Jonathan Weinberg, Geeks and Greeks 4-5 (unpublished manuscript), at http://www.law.wayne.edu/weinberg/geeksandgreeks.pdf (July 30, 2001) (exploring and contextualizing a series of statements regarding representation of the Internet user community).

81. The U.S. Department of Commerce has used slightly different language to make a similar point when it renewed the MoU. For instance, the Department noted that ICANN needed to strive "to ensure transparency and accountability in its processes and decision making" and "to increase its responsiveness to Internet stakeholders." Statement Regarding MoU, supra note 5. Transparency, accountability, and responsiveness are akin to openness and representation, but convey a slightly different set of goals.

82. iRegistrars.com, ICANN, at http://www.iregistrars.com/icann.html (last visited Feb. 23. 2004).

83. Robyn Weisman, New ICANN CEO Pledges Independence, NEWSFACTOR (Jan. 25, 2001), at http://www.newsfactor.com/perl/story/7000.html
} 
matically different turn. The board found that "a purely private organization will not work." 84

Scaling has proven hard for ICANN. ${ }^{85}$ As the scope of responsibility and number of constituents grows, so too does the difficulty of managing in a representative, open, and consensus-driven manner. ${ }^{86}$ Representation becomes more difficult as individuals grow further away from those who represent them, whether geographically or as a matter of sheer ratio. Whereas one representative used to have a constituency of 100, now he or she has a constituency of hundreds of millions (in the case of North America), or even billions of people (in the case of Asia). Similarly, openness - particularly in the sense of transparency - becomes harder with scale, as ot all decisions can be made by a small group of directors and officers in front of the world at large. ${ }^{87}$

\section{B. ICANN's Hybrid Structure and Its Drain on Legitimacy}

ICANN's complex hybrid structure is the root of its legitimacy problem. Rather than being chosen as the structure most able to manage the DNS, or to achieve the principles of openness and representation, ICANN's structure was a compromise in the worst sense of the

84. ICANN President Recommends a Roadmap for Reform, supra note 17.

85. See Posting of Kent Crispin, kent@songbird.com, to wg-c@dnso.org (Mar. 12, 2000), at http://www.dnso.org/wgroups/wg-c/Arc01/msg00909.html (discussing one of the particular types of scaling problems facing ICANN with respect to the introduction of new general Top Level Domains ("gLTDs")).

86. If the user community is defined either as the absolute number of Internet users globally or as the number of domain names registered, ICANN's number of constituents has grown markedly throughout its history. Likewise, as ICANN has introduced new gTLDs and has added the Uniform Domain -Name Dispute-Resolution Policy ("UDRP") process to its workload, its substantive responsibilities have grown. See Uniform Domain-Name Dispute-Resolution Process, at http://www.icann.org/udrp/udrp.htm (last updated Aug. 26, 2001).

87. ICANN has taken the laudable step of webcasting virtually all major sessions of its quarterly meetings to make its proceedings accessible to all who are interested. Webcasting, while an extraordinary technological advance for providing open meetings, nonetheless has its limitations. While access to a webcast is limited potentially by both bandwidth (particularly on the receivin $g$ side) and licenses to reach a certain number of end users (in the case of RealNetworks webcast production software), no ICANN webcast has yet hit server capacity. However, even the most aggressive and costly webcast can only offer a more or less passive experience to those who watch live streaming audio and video. If openness is simply to be able to watch and listen, then the webcast is surely sufficient for those with access to a relatively modern computer and a moderately fast Internet connection. Yet, if openness requires an ability to participate beyond submitting real-time text-based comments, then webcasting may come up somewhat short. Nonetheless, webcasting is a critically important element of ICANN's effort to make its proceedings accessible to a global audience. Over the past few years, however, ICANN has withdrawn some of the tools for participation related to these webcasts, like the prompt posting of substantial meeting notes and the ability to submit real-time comments, which had, in the past, been read to the board and were posted as part of the meeting archives. 
word. ${ }^{88}$ The designers attempted to blend the best parts of a corporation, a standards body, and a government entity, but they ended up with a structure that does not carry the legitimacy of authority or effectiveness of any of its component parts.

\section{ICANN as a Standards Body}

At least some of the organizations that predate ICANN, such as the IETF, could be characterized as standards-setting organizations, with varying degrees of formality in their decision-making processes. These loosely structured, volunteer-powered organizations traditionally created legitimacy of authority by using consensus to make decisions. The IETF, for instance, took no votes and had no formal leaders, but rather sought "rough consensus," making its decisions by listening to the "hums" of those persons present. ${ }^{89}$ Many of those active in ICANN today, particularly in the more technical capacities, come from the IETF tradition.

Vestiges of the standards body structure remain in ICANN. The powerful Supporting Organizations - which send members to the board of directors, and are responsible for providing guidance to the board on issues under the Supporting Organizations' jurisdiction are staffed almost entirely by volunteers. Often, they must pay their own travel expenses to attend ICANN's far-flung quarterly meetings. ${ }^{90}$ These Supporting Organizations have also been the venue for most bottom-up decision-making aspects of ICANN's structure.

ICANN, however, does not operate in the same manner as most standards bodies, such as the World Wide Web Consortium ("W3C"), the IANA, or the IETF. ${ }^{91}$ ICANN, despite its rhetoric about bottom-up organization, has a board of directors that exercises ultimate authority over the administration of a technical governance system to which millions around the globe implicitly agree. As more individuals, corporations, institutions, and governments develop an interest in the

88. See Sims infra note 264 and accompanying text (describing ICANN's structure as a compromise that does not do anything well).

89. See William A. Foster, Registering the Domain Name System: An Exercise in Global Decision-Making, at http://www.ksg.harvard.edu/iip/cai/foster.html (last visited Dec. 3, 2002); see also Jonathan Zittrain, Videotape: Lecture on Domain Names, ICANN, and Internet Governance (The Berkman Center for Internet and Society at Harvard Law School 2001), at http://cyber.law.harvard.edu/berkmancommons/icann.html. See generally IETF, Tao of the IETF: A Novices Guide to the Internet Engineering Task Force, (Aug. 2001), at http://www.ietf.org/tao.html (discussing the principles, decision-making methods, and history of the IETF).

90. An archive of ICANN's meeting sites since its inception in 1998 can be found at http://cyber.law.harvard.edu/icann.

91. There are, of course, many similarities between ICANN, the W3C, and the IETF, such as the fact that Supporting Organization staff and members pay their own travel expenses. The clear distinction lies primarily in the realm of how final decisions are made and what the opportunities are for recourse in the event of disagreement. 
DNS, and as the Internet becomes more and more central to people's lives, the informal standards-body model becomes less adequate. ICANN's increasingly formal and professional structure, including its CEO, staff, and board of directors, coupled with the attempted introduction of global elections, suggests a further move away from the model of its predecessors and their basis of legitimacy through consensus.

\section{ICANN as a Corporation}

Literally, ICANN is a not-for-profit corporation established in the State of California on September 30, 1998. ${ }^{92}$ Its governance structure vests virtually all power in the board of directors, who may delegate authority to a series of full time, professional officers, many of whom have had impressive careers before joining the ICANN staff. ${ }^{93}$ As a not-for-profit corporation, there are no shareholders per se, but the AtLarge Membership sought unsuccessfully to approximate that role during the two years it had voting power. ${ }^{94}$

Whether or not for-profit, the California corporate model seems particularly inadequate to create legitimacy for a global organization purporting to represent a worldwide populace and multiple crossborder constituencies. The corporate structure works well for organizations pursuing profit or engaged in advocacy, but it makes no sense given ICANN's specific public mission. Also, other than in the division of roles between officers and directors, and the limitation of liability, ICANN does not function like a traditional corporation. ${ }^{95}$

The corporate form's reliance upon the laws of a single U.S. state is a substantial liability to ICANN's legitimacy of authority. The interconnecting relationships between ICANN, the U.S. Department of Commerce, VeriSign (a California for-profit corporation), and other

92. For basic structural information regarding ICANN, see ICANN Corporate Documents, at http://www.icann.org/general/corporate.html (last visited Feb. 20, 2004); ARTICLES OF INCORPORATION, supra note 11.

93. See ICANN BYLAWS, supra note 25.

94. Not-for-profits can have "members," which are roughly equivalent to for-profit shareholders. ICANN, under pressure from the U.S. Department of Commerce, included in its original bylaws a reservation for a membership. ICANN BYLAWS art. II (Nov. 6, 1998), available at $\mathrm{http}: / / \mathrm{www}$.icann.org/general/archive-bylaws/bylaws-06nov98.htm.

95. Academic theories of the firm come up short when applied to the ICANN corporate form. The Coase-style "Theory of the Firm's" focus on transaction costs appears almost entirely irrelevant. See Ronald H. Coase, The Nature of the Firm, 4 ECONOMICA (ns) 386 (1937); Michael C. Jensen \& William H. Meckling, Theory of the Firm: Managerial Behavior, Agency Costs, and Ownership Structure, 3 J. FIN. ECON. 305 (1976). While perhaps marginally more apt, it is likewise hard to justify ICANN's corporate form along the lines of the "Nexus of Contracts" or "Web of Contracts" theories, especially given that the majority of stakeholders have made no contract with the ICANN corporate entity or with each other. See Frank H. Easterbrook \& Daniel R. Fischel, Contractual Freedom in Corporate Law, 89 COLUM L. REV. 1416 (1989); MichaEl P. DOOLEY, FundAMENTALS OF CORPORATE LAW (1995). 
corporate sponsors, already raise questions about the U.S. focus of this global entity. The corporate form holds ICANN back from expanding beyond its West Coast roots toward true representation of the global community. The ICANN headquarters in Marina del Ray naturally attracts staff from the United States who are interested in living in California. Every member of the board and staff has traditionally spoken English - the predominant language of both the Internet and the State of California. ICANN's efforts to broaden the geographic and cultural diversity of its At-Large Membership and board of directors are laudable, but any gains will be limited by ICANN's formal corporate structure. ${ }^{96}$

The study of business law suggests another critique of ICANN: its structure and grounding principles may be incompatible over the long term. Business law commentators, including Professor Stephen Bainbridge of UCLA, have shown that organizations choose one of two models for their internal governance: "consensus" or "authority." 97 The consensus model is most effectively employed when each member of the organization has the same information and members' interests are aligned. ${ }^{98}$ The consensus model can only work well in the absence of a substantial collective action problem. The authority model, by contrast, vests decision-making power in a central agency (in the corporate context, the board of directors), which grounds its decisions on input from other stakeholders. ${ }^{99}$ The authority structure works best when stakeholders have varying amounts of organization and misaligned interests. The corporate form in the United States provides, by statute, for an authority-style organization. ${ }^{100}$

ICANN, as a corporation, has the core structure of an authoritystyle organization. The power to decide is, after consultation, vested in the hands of a few. If Professor Bainbridge and his colleagues are correct, this authority structure fits ICANN. The many stakeholders in ICANN - ranging from the individual Internet user, to large corporations, to not-for-profit civil liberties organizations, to the European Union - have wildly varying levels of information and interests. ${ }^{101}$ Even if these disparities were not there, the Internet community is especially vulnerable to collective action problems. If ICANN were

96. It may be that any global organization would be forced to struggle with the problem of geographic location of operations. However, ICANN's structure as a California-based corporation exacerbates, rather than mitigates, this problem.

97. BAINBRIDGE, supra note 48 , at 192-94.

98. See id.

99. See id.

100. See id.; see, e.g., DEL. GEN. CORP. L. \$ 141 (2004).

101. ICANN's hybrid struct ure also involves a complex series of forums for various individuals to advocate for their interests. It is quite relevant that the power afforded these forums is not equally distributed. For instance, consumers have no official voting representative, whereas trademark owners have their own representative on the Domain Names Supporting Organization. 
only to care about managing the DNS well, these factors suggest that an authority structure might be appropriate and necessary for ICANN to succeed. However, the problem arises with the superimposition of the corporate form on ICANN's legacy of seeking consensus and its grounding principle of representation.

ICANN's corporate structure is not well-aligned with aspects of its history and its stated goals. Its commitment to openness and representation clashes with its corporate form to drain much of ICANN's dwindling legitimacy of authority. The theories of business law, applied to the context of ICANN, suggest that if ICANN must remain a corporation, even in form only, then it may be doomed to fail on its own terms.

\section{ICANN as a Government Entity}

ICANN also embodies elements of a government entity. As with other analogs, the parallel is not exact: ICANN lacks many of the traditional hallmarks of a government entity, such as enforcement powers. However, ICANN's quasi-governance role, coupled with its stated goal of representation, the Election of 2000, and its usage of multiple attributes of the administrative agency model, renders the analogy to a government entity informative. ${ }^{102}$

The story of ICANN's formation resembles the formation of a state. In the political theory of thinkers like Hobbes, Locke, and Rousseau, people are born into a state of nature. While they are free in that they have no sovereign, they enslave themselves through the anarchy that ensues. ${ }^{103}$ In the Internet context, the first several years of mass Internet usage were characterized by a call to arms to keep the space free of sovereigns, much like a state of nature. Former Grateful Dead songwriter John Perry Barlow's "Declaration of the Independence of Cyberspace," written in Davos, Switzerland, in 1996, is the classic example of such a call to arms. "Governments of the Industrial World ... are not welcome among us," Barlow wrote of cyberspace. ${ }^{104}$ "I declare the global social space we are building to be naturally independent of the tyrannies you seek to impose on us." ${ }^{105}$ The seams of the state of nature begin to show, however, as the space be-

102. As noted above, Mueller prefers this analogy of ICANN as a government. See MUELLER supra note 24; see also Weinberg, supra note 4, at 187.

103. As Rousseau wrote, "Man is born free, and everywhere he is in chains." JEAN J. Rousseau, The Social Contract, in ROUSSEAU'S POLITICAL Writings 85 (Alan Ritter \& Julia Conway Bondanella eds., Julian Conway Bondanella trans., Norton Critical ed. 1998) (1762).

104. JOHN P. BARLOW, A DECLARATION OF THE INDEPENDENCE OF CYBERSPACE (Feb. 28, 1996), at http://www.eff.org/ barlow/Declaration-Final.html.

105. Id. But see LESSIG, supra note 39; Neil W. Netanel, Cyberspace Self-Governance: A Skeptical View from Liberal Democratic Theory, 88 CAL. L. REV. 395, 397-99 (2000). 
comes crowded and interests begin to diverge. Fights ensue, which in turn cannot be resolved amicably in the absence of a sovereign. In cyberspace, a number of fights have begun: disputes over technical governance of the Internet, use of certain domain names, and expansion of general Top Level Domains ("gTLDs") are among the earliest of those fights. To establish positive liberties, people enter into a social contract by vesting power in a sovereign to govern their collective lives. In the cyberspace story, some of those frustrated by the state of nature entered into a series of agreements culminating in ICANN, which was created to lend order to the growing chaos.

This parallel, though inexact, has some merit, especially in light of ICANN's experiment to acquire its legitimacy drectly from the people of the Internet community. While cyberspace is not physical space and the global community of Internet users is not joining a nation-state, certain Internet users have agreed to the ICANN system as a means of determining how to co-exist in some parts of cyberspace. Those who acknowledge ICANN's authority, who buy into the principles of openness and representation, are agreeing to the superimposition of a certain sovereignty and a series of rules to live by with respect to the DNS. ${ }^{106}$ In partic ular, anyone who wishes to obtain and hold a domain name must agree to ICANN's sovereignty. Rather than thinking of a governing entity as a state per se with enforcement powers, the basic notion of joining into a social contract and submitting to a sovereign holds in the cyberspace context. ${ }^{107}$

The shortcomings of the parallel to a government entity are immediately apparent. ${ }^{108}$ ICANN is not, strictly speaking, a government entity. ${ }^{109}$ It neither sought nor attained the consent of those it governed at the time of its formation or subsequently. As Professor Froomkin argues forcefully, ICANN sought to carry the legitimacy of the IETF forward but has failed to do so. ${ }^{110}$ Also, its inability to en-

106. This notion squares with Rousseau's philosophy of the emergence of the state: [T] he act of association includes a reciprocal commitment between the public and the private individuals composing it, and that each individual, contracting, so to speak, with himself, finds himself committed in two ways: namely, towards private individuals as a member of the sovereign, and toward the sovereign as a member of the state. ROUSSEAU, supra note 103, at 93-94.

107. Another way of conceiving of ICANN as akin to a state is to note the extensive power of formal states through the Governmental Advisory Committee, all the more so because of the changes to the ICANN by-laws after the September 11th attacks on the United States. See Wolfgang Kleinwaechter, From Self-Governance to Public-Private Partnership: The Changing Role of Governments in the Management of the Internet's Core Resources, 36 LOY. L.A. L. REV. 1103, 1121 (2003).

108. See generally Weinberg, supra note 4.

109. ICANN grounds its authority in a sole source contract with the U.S. government. More than seventy-five governments participate through the General Advisory Committee. ICANN itself is not formally vested with the powers of a government entity, nor is it properly thought of as a treaty organization.

110. See Froomkin, supra note 33. 
force its decisions is a major divergence from the government model. ICANN's scope is so limited that there is little room to argue that ICANN governs people's lives in the way that most governments do. Its organization stems from neither a series of substantive rights nor a theory of procedure. ${ }^{111}$ Some critics of ICANN continue to cling to Barlow's circa 1996 theory that the Internet cannot or should not be governed in any way, ${ }^{112}$ and ICANN's leaders have consistently claimed that ICANN does not govern, but rather coordinates a technical system. ${ }^{113}$

The ICANN Election of 2000 brings this issue of its parallel to a government entity into relief. Despite the incompleteness of the parallel, ICANN's increased efforts to achieve representation of the global community of Internet stakeholders suggested, though briefly, a move toward a democratic institution. Other forms of organization, such as the corporation, rely on fiduciary duties rather than the notion of direct representation. ${ }^{14}$ In the shareholder-manager scenario of a corporation, for instance, the board and officers have a fiduciary responsibility to the shareholders and have an obligation to increase shareholder value. However, the board and officers do not nec essarily represent all or even a particular subset of those who contributed capital. The relationship is better described by agency rather than by representation. The notion of a director specifically representing the interests of stakeholders and voicing their interests to the decision makers, as ICANN has effectively sought to do through the At-Large Membership and the elected directors, draws the parallel of ICANN's structure away from the corporate model and closer to a government.

111. See, e.g., Frank I. Michelman, How Can the People Ever Make the Laws? A Critique of Deliberative Democracy, in ESSAYS ON REASON AND POLITICS: DELIBERATIVE DEMOCRACY 152 (James Bohman \& William Rehg eds., 1997).

112. But see LESSIG, supra note 39, at 24-29 (arguing against the idea that the Internet has a nature that is unregulable).

113. For instance, ICANN Chairwoman Esther Dyson took issue with the use of the term "Internet governance" as being part of ICANN's job description. In response to a question posed by Ralph Nader and James Love, Dyson wrote, "ICANN does not 'aspire to address' any Internet governance issues; in effect, it governs the plumbing, not the people." Letter from Esther Dyson, Chairwoman, ICANN, to Ralph Nader and James Love (June 15, 1999), available at http://www.icann.org/correspondence/dyson-response-to-nader-15jun99.htm. But see Andrew McLaughlin, Remarks at Harvard Law School Internet \& Society 1999 class (Sept. 16, 1999), at http://cyber.law.harvard.edu/is99/scribes2.html (transcription by Benjamin Edelman) (“'ICANN does technical coordination, not Internet governance.' That's the party line. But the truth is that technical coordination is in some ways a lot like governance."). For uses of the term "governance" in relation to ICANN in common parlance, see articles such as Internet Governance: Domain Strain, THE ECONOMIST, Mar. 10, 2001, at 64.

114. In the corporate setting, voting is an important attribute of most state-mandated systems, but shareholders - the "voters" - are not strictly speaking represented by particular directors. See FrANK H. EASTERBROOK \& DANIEL R. FiSCHEL, THE ECONOMIC STRUCTURE OF CORPORATE LAW 63-89 (1991); see also Lucian Bebchuk, A Framework for Analyzing Legal Policy Transactions Proxy Contests, 78 CALIF. L. REV. 1073 (1990). 
ICANN is not purely a standards body, a corporation, or a government entity. It has elements of each, but none of these models suffices on its own to describe ICANN's current hybrid structure. This conclusion leaves open a vexing question, which has both positive and normative elements. What kind of institution is ICANN? What kind of institution should it be? Where does its legitimacy come from? The answers to these questions are not clear. It is important, though, to recognize that ICANN strives to operate by clear founding principles in a highly complex structure - the complexity of which makes fidelity to these principles all the more challenging. That complexity was also an opportunity to test the Internet's ability to enable a new, more democratic and empowering - though ultimately unsuccessful form of decision making.

\section{Does ICANN Need Legitimacy: Does It Matter Whether ICANN Lives Up to Its Principles?}

ICANN has caught the imagination of certain technologists, scholars, lawyers, and businesspeople from various fields, but remains virtually unknown to the general public. ${ }^{15}$ A vast majority of the roughly 600 million people who use the Internet to gather information, communicate via e-mail, or shop online appear to have little interest in the technical administration of the DNS. ${ }^{116}$ If many people who use the Internet neither know, nor much care, about what ICANN does, does ICANN even need to legitimate its authority? Does it matter at all whether ICANN lives up to its founding principles? Moreover, does it matter what sort of governance structure ICANN has? One prevalent line of argument, that ICANN's work is so arcane and remote from the lives of everyday people, suggests that the answer to these questions is "no." However, in light of ICANN's current role,

115. The Markle Foundation commissioned a survey which cited the lack of knowledge about ICANN as a major concern. See JERRY BERMAN ET AL., ICANN'S GLOBAL ELECTIONS: ON THE INTERNET, FOR THE INTERNET, ii, iv (Mar. 22, 2000), at http://www.markle.org/news/icann_report.pdf .

$[\mathrm{N}]$ early every member of the Internet community with whom we spoke, as well as respected outside observers, identified fundamental problems with the current plan for the election being put in place by ICANN. Some of these problems can be addressed through improvements in the proposed election process, but others are the products of conflicting goals for the election itself. These problems are compounded by the fact that most of the electorate envisioned by ICANN does not know what ICANN is or what it does. In short, what we found is a proposed election process for ICANN viewed with almost

Id. uniform skepticism by informed observers.

116. See, e.g., eTForecasts, Internet User Forecast by Country, at http://www.etforecasts.com/products/ES_intusers.htm (last visited Feb. 11, 2004) (providing one analysis of world-wide Internet usage, ordinarily pegged between 500 million and 600 million). 
and its importance to the global economy and to the Internet, a network of increasing importance to the lives of people in more than one hundred countries, the answer to these questions is "yes." ${ }^{\text {"117 }}$ ICANN's structure and management are important because ICANN's mission is important, and also because ICANN was thought to have presented an extraordinary opportunity to experiment with a new medium's power of institution-building on a global scale. Furthermore, observers have posited that ICANN should serve as an experiment in strengthening participation in democratic institutions generally through innovative use of the Internet. ${ }^{18}$ The outcome and lessons learned from ICANN's experiment are significant because it is viewed by some as a test case for innovation in technology-powered democratic governance.

ICANN is among the few organizations recognized formally, at least by the US. government, as empowered to administer certain critically important technical procedures that affect the entire Internet. ${ }^{119}$ Since the Internet is a network that joins hundreds of millions of people across the world, and as such has prompted many powerful interests to become involved in its activities, ICANN may well be "the most important Internet organization you've probably never heard of." ${ }^{\prime 20}$ Evidence of the importance of ICANN's work is primarily qualitative in nature, but ample in quantity. Naturally, governments have focused substantial attention on ICANN. On several occasions, members of the U.S. Congress have held hearings and isued public statements that, at least in part, question whether the Department of Commerce-backed ICANN had garnered too much authority over a public resource without sufficient legitimacy. ${ }^{121} \mathrm{Sev}$ eral institutions of the European Union have focused on ICANN, re-

117. For a consideration of why ICANN does or does not matter, see Zittrain, supra note 37.

118. See, e.g., Steven Hill, ICANN: Secret Government of the Internet? The Fight Over Who Will Control the Web, IN THESE TIMES (May 15, 2000), at http://www.inthesetimes.com/issue/24/12/hill2412.html.

119. Other important technical procedures that affect people's ability to access the Internet are administered by the International Telecommunications Union ("ITU'), which is formally recognized by 189 governments. See Int'l Telecomm. Union, Overview, at http://www.itu.int/members/index.html (last updated Mar. 10, 2004).

120. Dan Gillmor, ICANN Election Carries Hope of Needed Change, COMPUTERWORLD (Oct. 30, 2000), at http://www.computerworld.com/cwi/story/ 0,1199,NAV47_STO53016,00.html

121. See, e.g., Declan McCullagh, Congress to Enter ICANN Fray, WIRED.COM (Mar. 14, 2002), at http://www.wired.com/news/politics/0,1283,51041,00.html. It is worth noting that no formal Congressional action has been taken to reign in ICANN since its inception, despite a lack of consensus (or a lack of interest) in Congress as to the propriety of ICANN's work and legitimacy of its authority.

There is an interesting question set aside here that has yet to be fully examined in the literature of Cyberlaw: to what extent should we regulate the Internet as a global public utility (in the general sense of the term "utility")? If so, what implications would this insight have on Internet law and regulations? 
viewing, among other is sues, its implications for competition and data privacy. ${ }^{122}$ Roughly seventy-five government representatives partic ipate in ICANN through the Governmental Advisory Committee ("GAC"). ${ }^{123}$ Academics, including members of the ICANN board, law professors, computer scientists, and public policy scholars, have written about ICANN and participated in its formation. The news media has covered its establishment and growth. Hundreds of articles in the trade press, such as Wired, C|Net, The Industry Standard, and Red Herring, both in print and online, have told ICANN's story to technologists; mainstream newspapers, too, from cities around the world have published stories for the casual observer. ${ }^{124}$

Much of the reason why people care about ICANN - and the manner in which it governs and is governed - revolves, not surprisingly, around a dwindling, but nonetheless substantial, amount of money. ${ }^{125}$ Among other things, ICANN oversees the process by which second-level domain names are given out to businesses, NGOs, and anyone else who wants to establish a website on the Internet. The power to assign and manage certain domain name registry systems turned Network Solutions into a corporation for which VeriSign was willing to pay $\$ 21$ billion in $2000 .{ }^{126}$ A single domain name, "business.com," is believed to have commanded a $\$ 7.5$ million sale price, albeit at the height of the mania surrounding Internet expansionism. ${ }^{127}$ Applicants for the rights to manage new gTLDs anted up $\$ 50,000$ each to ICANN simply to put forward a proposal, with no claim to a refund in the event of failure. ${ }^{128}$ Other aspects of ICANN's work, such as setting certain technical standards, could have substantial additional

122. See EU Plans ICANN Study, HEISE ONLINE (Dec. 11, 2001), at http://www.heise.de/english/newsticker/news/23317.

123. See Governmental Advisory Committee, at http://www.gacsecretariat.org/web/ index.shtml (last visited Mar. 5, 2004).

124. Citations are far too numerous to mention exhaustively here. See, e.g., Internet Governance: Domain Strain, supra note 113; Web Domain Group Skirts Controversy, N.Y. TIMES, Mar. 14, 2001, at C4.

125. The amount of money at stake with ICANN's decisions in 2004 is surely lower than it was at the height of the Internet bubble, for instance, in March 2000. Still, a future is conceivable in which more and more money changes hands to reserve more and more $\mathbf{b}$ main names across a broader range of gTLDs. One might also consider the sale price of Network Solutions to VeriSign (tens of billions of dollars) and the subsequent sale of assets of Net work Solutions by VeriSign (hundreds of millions of dollars).

126. See, e.g., Damien Cave, Is VeriSign a Network Solution?, SALON.COM (Mar. 8, 2000), at http://www.salon.com/tech/log/2000/03/08/verisign_nsi/index.html.

127. See, e.g., Amy Schein, Business.com, Inc., at http://www.hoovers.com/ free/co/factsheet.xhtml?COID $=103149$ (last visited Feb. 23, 2004); see also Scott Rosenberg, Their Names Are Legion, SALON.COM (Mar. 10, 2000), at http://www.salon.com/tech/col/rose/2000/03/10/domain_names/index.html. A new round of gTLD proposals may be underway shortly as the seventh gTLD of the first round of gTLD extensions comes on line.

128. ICANN reportedly collected $\$ 2.35$ million through the new proposal process. See Mary Mosquera, Domain Name Space About to Burst Open, TECHWEB.COM (Oct. 31, 2000), at http://www.techweb.com/wire/story/TWB20001031S0018. 
commercial importance. Though valuations of domain name-related entities and contractual rights have fallen markedly over the past few years, ICANN's work nonetheless draws commercial interest.

The fear of "mission creep," and the related concern about ICANN's governance activities, also rank among the reasons for interest in and concern about ICANN's management structure. ${ }^{129}$ ICANN stands alone among global institutions with any claim to $\mathrm{b}-$ gitimacy in managing certain affairs related to the core systems of the Internet. ${ }^{130}$ ICANN's leadership has consistently downplayed this risk of mission creep and advocated "tight focus" on a narrow mandate. ${ }^{131}$ While its mandate is indeed limited today to the naming and numbering schemes, some observers (including members of the House and Senate of the U.S. Congress) have expressed fears that ICANN could extend its influence to other Internet governance tasks. ${ }^{132}$ As remote as the possibility of "mission creep" may seem, and as believable as ICANN's leaders may sound, as ICANN comes under increasing fire, this concern may have merit even if ICANN per se does not extend its reach. ${ }^{133}$ Cyberspace may be different enough from terrestrial space that some other institution may seek to establish a claim to govern other matters online, such as civil liberties or other issues that may be more important to individual users of the Internet. ${ }^{134}$ Related concerns, like the fear that industrial societies will be seized by a technical elite, also feed into the importance of ICANN's management despite its obscurity. ${ }^{135}$

129. See, e.g., COMMON CAUSE \& THE CTR. FOR DEMOCRACY AND TECH., THE ICANN AT-LARGE ELECTION STUDY (Jan. 2000), at http://www.commoncause.org/icann/ roundtable/background.htm.

130. It is conceivable that the International Telecommunications Union ("ITU") might claim to be involved in roughly the same business, given its regulatory authority over aspects of the telephone numbering system.

131. STUART LYNN, PRESIDENT'S REPORT: ICANN - THE CASE FOR REFORM, INTERNET CORPORATION FOR ASSIGNED NAMES AND NUMBERS (Feb. 24, 2002), at http://www.icann.org/general/lynn-reform-proposal-24feb02.htm.

132. See John StUART MiLl, CONSIDERATIONS ONREPRESENTATIVE GOVERNMENT 2627 (Gateway ed. 1962) (1861) (suggesting that in considering a structure of govemance, one should consider not just the legitimate scope of what the entity is intended to cover by its mandate, but also those areas to which the entity might extend its reach for bad reasons).

133. Curiously enough, Congress itself may contribute to this fear of mission creep with such proposals as the plan to mandate establishment of a ".kids" gTLD. Such a plan would require decisions about what content is appropriate for what audiences and would, by necessity, involve monitoring and censo ring certain speech. See, e.g., Patricia Jacobus, ICANN Staff Opposes ".kids," “.xxx” Domains, C|NET (Nov. 10, 2000), at http://news.com.com/2100-1023_3-248455.html.

134. See Hill, supra note 118.

135. But see Harold Loeb, LIFE IN ATECHNOCRACY : WhAt IT Might BE LiKE (Syracuse Univ . Press 1996) (1933). But see Technocracy, Inc., A Statement of the Social Objectives of Technocracy (Mar. 1933), at http://www.technocracyinc.org/articles/ social-objectives.html (advocating a movement to replace politicians with engineers and "technologists"). 
ICANN's management structure matters, too, because of the need to develop new global governance structures for the technical architecture of the Internet. ${ }^{136}$ Few issues are able to touch the lives of so many across such a broad geographical and functional spectrum, even indirectly, as ICANN's mandate does. While the world's societies are certainly divided into technology haves and have-nots, ${ }^{137}$ often along purely economic lines, the breadth of Internet usage and transactions across national boundaries continues to expand, though not at the rate predicted a few years ago. ICANN is an institution that can potentially become relevant to the lives of people in every country in a way that few other institutions in history have. ${ }^{138}$ This global reach highlights the potential importance of the ICANN experiment to the future of Internet governance. Some people care about ICANN's management because they fear expanding U.S. hegemony, the English language, or the power of multinational corporations. ${ }^{139}$ Others see ICANN's potential reach as an opportunity to energize Internet users across mtional borders into forging a global community and to test the Internet's ability to power global democratic institutions. Those concerned with how we will move forward in making technical governance decisions, particularly with the increased concern over abuse of the network by spammers and others, seek a new model for how to tackle this looming problem. ${ }^{140}$ For all of these reasons, ICANN matters, and the outcome of its experiments in representation is worthy of scrutiny.

136. See Farber, supra note 1 (arguing that "an intensive, international study be started at once, with a mandate to propose detailed and meaningful paths for the Internet's development, operations, and management").

137. The global digital divide is yet another issue that warrants extensive study of its own. The relevance of the digital divide in the ICANN context has yet to be explored extensively in the Cyberlaw literature, though there has been some discussion of the limited particip atory role of developing countries in ICANN, despite substantial effort to reach out to leaders in developing countries on the part of ICANN's staff, board, and activists. For example, the number of votes cast in North America and Europe in the Election of 2000 dwarfed the number of votes cast in Africa. See generally Benton Foundation, at http://www.benton.org (last visited Mar. 5, 2004); Digital Divide Network, at http://www.digitaldividenetwork.org/content/sections/index.cfm (last visited Mar. 5, 2004) (discussing the digital divide, though not explicitly in the context of ICANN).

138. Arguably the United Nations, numerous other treaty-based organizations, certain NGOs, churches, and empires have had comparable global reach to that of ICANN.

139. See, e.g., George Monbiot, Captive State: The Corporate Takeover of BRITAIN (2000); see also Captive State, at www.captivestate.com (last visited Mar. 5, 2004); Williams, supra note 5.

140. See also Kiri Blakeley, Spam: It's Worse Than You Think, FORBES.COM(Nov. 11, 2003), at http://www.forbes.com/2003/11/11/cz_kb_1111spam.html 


\section{THE FAILURE OF THE EXPERIMENT IN LEGITIMACY THROUGH OPENNESS}

The crisis of legitimacy that spurred the Election of 2000 stems from ICANN's failure to garner legitimacy of authority through openness. The experiment in openness failed for two reasons: first, there was a fundamental confusion in what was meant by "openness," and second, ICANN's hybrid organizational form obscured the decisionmaking process so that even if it had wanted to, ICANN's leadership could not listen to Internet user input.

\section{A. Confusion about "Openness"}

At least three possible conceptions of what "openness" means have clashed in the development of the ICANN model. ${ }^{141}$ First, activists have sought openness in the sense of an ability not only to see but also to participate in the decision-making process. This activist sense of openness is roughly consistent with the view of certain scholars that ICANN ought to achieve openness in the Habermasian ideal: a high level of discourse prior to reaching decisions. ${ }^{142}$ Second, some conceive of openness as a variant of leading free software guru Ric hard Stallman's non-proprietary model of the development of intellectual goods, in which the form of the final outcome is what matters most. ${ }^{143}$ Openness, in this second sense, is about positive freedom to do whatever users want with the output of the process. ${ }^{144}$ Third, yet others have set forth an Eric Raymond-style production model, in which openness is meant as a process by which a good end is achieved. $^{145}$

In the first sense of openness, ICANN is meant to be managed so as to allow people to see what is going on and to be heard when they

141. This concept of the three clashing senses of "openness" is directly attributable to conversations with Professor Jonathan Zittrain during the development of this paper. A far more subtle view of meanings of openness in the context of standards setting may be found in Ken Krechmer, The Principles of Open Standards, STANDARDS ENG'G, Nov./Dec. 1998, at $1-6$.

142. The leading proponent of this position is Professor A. Michael Froomkin. See generally Froomkin, supra note 33.

143. See Richard Stallman, Why "Free Software" Is Better than "Open Source," in FREE SOFTWARE, FREE SOCIETY : SELECTED ESSAYS OF RICHARD M STALLMAN (Joshua Gag ed. 2002), available at http://www.gnu.org/philosophy/free-software-for-freedom.html (last visited Mar. 5, 2004).

144. Id. It is essential to note that, in the free software context, the end user must abide by a series of rules set out in a "copy left" agreement and then subject future users of the code to identical requirements.

145. See ERIC S. RAYMOND, THE CATHEDRAL AND thE BAZAAR (1999), available at http://www.catb.org/ esr/writings/cathedral-bazaar/cathedral-bazaar (last revised Sept. 11, 2000). 
express their opinions. ${ }^{146}$ The activist understanding of openness hinges largely on the ability not just to see, but also meaningfully to affect the decision-making process. ${ }^{147}$ Much of the criticism that ICANN has sustained to date has been proffered by those who believe that they were either excluded entirely from the process or afforded little meaningful voice in developing ICANN's structure and system. ${ }^{148}$ One ICANN participant described the point at which he lost faith in ICANN:

My belief in ICANN died when, at the Geneva meeting, I was presented with an outline of what would actually happen, and watched that happen (specifically, but not exhaustively, watching an unelected board be appointed, then watching that board take its technical mandate and turn it into a regulatory vehicle). ${ }^{149}$

This commentary suggests an activist understanding of the term "openness" in the ICANN context. Openness, to these critics of ICANN, meant not only that one could watch things happen, but additionally that one could participate in the process of reaching the decision that instead was later presented as a fait accompli.

In a related vein, other stakeholders have sought openness at ICANN in the sense of clarity and reliability of process. ${ }^{150}$ This clarity is necessary to empower users wishing to contribute to the decisionmaking process, and also to businesses seeking to make investments based upon the regulatory environment set up by ICANN. This comment has arisen primarily in the context of proposals for the extension of gTLDs, in which those who favor particular extensions seek to de-

146. See Tao of the IETF, supra note 89; IETF, Overview of the IETF, at http://www.ietf.org/overview.html (last visited Mar. 5, 2004).

147. See Leon Koay \& Michael Richardson, Openness and Transparency, at http://cyber.law.harvard.edu/icann/workshops/LA/papers/openness.html (last visited Feb. 7, 2004) (describing some early criticisms of ICANN's lack of openness in terms of preventing understanding of, or access to, the decision-making process).

148. ICANN't Believe What They're Doing, supra note 58 ("ICANN Interim President Mike Roberts said most of the criticism of his group relates to 'process'....").

149. Posting of Christopher Ambler, cambler@iodesign.com, to bwg-nfriends@fibertron.com (Oct. 14, 1999) (on file with author). This generally very wellinformed critic, Christopher Ambler, may have had his facts incorrect: there was no ICANN at the time nor has there been a Geneva ICANN meeting; he is likely referring to an International Forum on the White Paper meeting in July 1998. See IFWP-Geneva Archive, at http://cyber.law.harvard.edu/icann/ifwp-geneva-archive (last visited Feb. 7, 2004).

150. See, e.g., Bret Fausett, My Public Comment (Oct. 30, 2003), at http://blog.lextext.com/blog/_archives/2003/10/30/5324.html (arguing, as counsel to NextDNS, in favor of "clarity" in the process of assigning new top-level domains). 
termine the level of risk associated with the investment necessary to propose a new gTLD. ${ }^{151}$

The second and third potential meanings of openness in the Internet lexicon - the Stallman-style and Raymond-style versions, for short - have been less prevalent in the discourse but certainly present. The Stallman-style version of openness, in which the output is meant to be free, as in non-proprietary, is hard to square with the nature of what ICANN is doing. In the sense that ICANN seeks to allocate a series of necessarily proprietary resources, a non-proprietary series of outcomes is inherently difficult to achieve in ICANN's context. $^{152}$ To maintain a stable system, ICANN can direct requests for cocacola.com to only one address on the Internet. This conceptual difficulty is revealed in the reaction to the Free Software Foundation's proposal, over Stallman's signature, to develop a ".gnu" top-level domain. ${ }^{153}$ ICANN has not achieved openness in the sense of nonproprietary outcomes of the decision-making process.

In the Raymond-style conception of openness, the goal is to achieve the best outcome through a non-proprietary process. ${ }^{154}$ It is in this sense of openness that ICANN might be defended most vigorously. ICANN has certainly enabled many members of the user community to participate in the development of its process, either through involvement in a Supporting Organization or by making comments directly to the board. Likewise, one might reasonably contend that the outcome of ICANN's work has been at least acceptable, and surely far better than it might have been. If the notion of openness is that the development of goods ought to involve as many users as possible to produce the highest-quality output possible - without prescribing precisely the manner in which the output is developed or prejudging its outcome - ICANN fares reasonably well. ${ }^{155}$

151. See Public Statement from the Internet Challenge to Afilias, Neulevel, ICANN, and DoC (Apr. 5, 2002), at http://www.gtldregistries.org/mailing/gtld/200204/0014.html (referring to a "lack of openness" in the gTLD context); see also STUART LYNN, A PLAN FOR ACTION REGARDING NEW GTLDs (Oct. 18, 2002), at http://www.icann.org/committees/ ntepptf/new-gtld-action-plan-18oct02.htm (describing the process for introducing new gTLDs).

152. I have found no evidence to suggest that Richard Stallman himself argued in favor of an ICANN that is open in the sense that I ascribe to him here. I mean only to refer to an important understanding of the term "openness" for which he has become a standard-bearer.

153. See Richard Stallman, ICANN Yokohama Meeting Topic: Introduction of New Top-Level Domains Expression of Interest \#12 (July 10, 2000), at http://www.icann.org/ yokohama/eoi12.htm; see also FSF Proposes .gnu TLD to ICANN, SLASHDOT, at http://slashdot.org/articles/00/07/12/1710226.shtml (last visited Feb. 7, 2004) (reacting to the proposal).

154. As with Stallman, I have no reason to believe that Eric Raymond has taken such a position with respect to ICANN; rather I credit him with development of a certain widespread strand of thinking about what the term "open" means.

155. Stakeholder opinion is far from unanimous on this particular point. See, e.g., Farber, supra note 1 (arguing that ICANN's management of the DNS is inferior to many alternatives). 
This confusion has caused a fundamental problem for ICANN's experiment in legitimacy through openness. ICANN's leadership seems to have adopted the Raymond-style conception of openness, whereas the Internet user community and ICANN's critics have adopted the activist sense of openness.

\section{B. The Limits of Public Input in Decision Making at ICANN}

ICANN's leadership has expended a great deal of effort to live up to its founding principle of openness. However, this effort was crippled by the misunderstanding between ICANN's leadership and the Internet user community over the meaning of "openness." ICANN's leadership was able to achieve a Raymond-style openness by including many people through its public message boards, but a systematic review of public input on a series of key issues suggests that users could not reasonably think that ICANN was open in the activist sense of the word. ${ }^{156}$ Even when the majority of users agreed on a given

156. This review, examining the majority of public commentary on ICANN's online forums, was conducted by the Berkman Center over the past year. For a web-based compilation of the data, see John Palfrey et al., Public Participation in ICANN: A Preliminary Study, Berkman Center for Internet \& Society at Harvard Law School, at http://cyber.law.harvard.edu/icann/publicparticipation (last visited Feb. 12, 2004).

Methodology: After selecting publicly archived mailing lists and forum.icann.org, see infra note 161 and accompanying text, as the focus of our research, we wrote a collection of Perl scripts that systematically downloaded and sorted approximately 100,000 mailing list emails and forum comments. The data we gathered do not reflect all discourse that took place in the mailing list and on forum.icann.org; some archives are no longer available online and human error may have led to the omission of other undiscovered data sets. We collected data from all of the forum.icann.org web pages published before July 1, 2003 and all of the mailing lists with archiv es on the DNSO/GNSO web pages.

After downloading and sorting the data, we performed a channel analysis, in which we graphically inspected the data from a variety of sub-populations to find out whether a random sample was appropriate. We determined mathematically that the public comments that we reviewed represented a Pareto distribution. We then selected four issues that we determined to be fairly representative of the types of decisions that ICANN has made.

In analyzing each of our four target issues, we decided at the outset whether it was feasible to analyze every available comment within our population of interest or to sample from the population. When fewer than 400 comments were made regarding an issue, we included all of the comments in our analysis. When more than 400 comments were posted, we randomly sampled from the population of comments. Sample sizes were calculated at $95 \%$ confidence levels with a confidence interval of plus/minus 5\%. If a distribution was particularly skewed — when a few users post a significant portion of the comments - we sampled the dat a twice: once for the opinions of the majority of users, and once for the opinions of the heavy users. The sample sizes for these bifurcated populations were calculated at the same power levels as the original sample sizes. For all of the instances where this was a concern, we discovered that the users dominating the conversation were predominantly posting off-topic messages or "flames" irrelevant to the serious consideration of a given matter. We have sought to include only comments that we deemed to be substantive in the presentation of our issue analysis data.

Researchers familiar with the issues, but generally unfamiliar with the individuals posting comments to the message boards, coded each comment within the context of the issue being analyzed. What the rater looked for in each post directly reflected the issue that was being discussed on that particular board. If, for example, the message board was intended to gauge 
issue, they could not presume that their input would substantially impact the decision-making process of ICANN's board. ${ }^{157}$ In some instances, input from the user community may have had an impact upon the outcome of a given decision, but the data suggest that the board tended to rely more heavily upon staff recommendations and the input of the Supporting Organizations (in which users may also participate). ${ }^{158}$ The Internet user community could not reliably expect that their input through these online forums would result in board consideration of their interests. In other instances, too few public comments were posted to provide a strong indication of Internet user community support. ${ }^{159}$ These findings reaffirm, at least to a limited extent, the intuition of the many critics who have questioned the extent to which ICANN has lived up to its principle of openness. ${ }^{160}$ In light of these findings, reform of the ICANN decision-making structure should, at a minimum, clarify the channels for input from the user community to the decision makers and ensure that user expectations about the effect of their input are met.

ICANN has opened a range of Internet-based channels through which members of the global Internet user community may submit comments to ICANN's leadership about matters general and specific. Two of these channels were the focus of this consideration of public participation at ICANN: the public, Internet-based mailing lists and the topically oriented web-posting spaces. ${ }^{161}$ These channels have been widely used as a means of participation and have been largely

support for the implementation of VeriSign's proposed Wait-Listing System, comments were tabulated as supportive of the proposal, in opposition to the proposal, or off-topic. If a rater experienced difficulty determining the intention of the posting user, a second rater was brought in to collaborate and, in all cases, consensus was reached as to the intention of the user. We performed a quality-assurance check of our data analysis, in which a researcher other than the initial researcher reviewed the raw and compiled data. Prior to this publication, I presented draft, initial findings of these data in three settings: before a group of Internet law professors in August 2003, at a seminar on Internet governance at the Kennedy School of Government in October 2003, and at a research meeting of fellows at the Berkman Center for Internet and Society at Harvard Law School in November 2003.

157. Id.

158. In many instances, users chose to contribute their ideas through the Supporting Organizations. However, for the purposes of our study, it is extremely difficult to differentiate user input from the input of large group interests, such as the corporate interests

159. Consider, for instance, the thin volume of commentary on the reassignment of the "org" domain from VeriSign to a new operator. It is hard to know whether to blame ICANN or the global Internet user community for the fact that there was such anemic public commentary posted about such an important issue. One hypothesis is that users recognize that even their substantive comments are ignored by ICANN's board. On the contrary, however, users have continued to post commentary regarding ICANN's reform proposals well after the reassignment of the ".org" top-level domain came up for a vote before the ICANN board. In any event, the paucity of comments in some cases points to the inadequacy of these online forums alone to solicit and incorporate Internet user community input in the decision-making process of such an institution.

160. See Koay \& Richardson, supra note 147.

161. For the primary example of these web-post ing spaces, see ICANN Public Forum, at http://forum.icann.org/ (last visited Feb. 21, 2004). 
archived online, allowing for a relatively reliable data set for analysis. ${ }^{162}$ This study involved a review of approximately 100,000 messages between late 1998 and July 1, 2003. We chose to analyze four topics of broad interest to the Internet community. On these four topics, we considered both the direct user input to the ICANN board of directors as well as the other forms of input that the board considered, such as recommendations from the Supporting Organizations and outside experts. This study demonstrates that users cannot reasonably presume that their input through these two channels, even when the user community overwhelmingly supports a certain position, might affect the board's decision making. Based on this review, these public forums for global user community participation do not contribute meaningfully to an open and representative ICANN decision-making process.

The four topics considered closely in this study are: (1) the introduction of new top-level domains in 2000 (both contested and noncontested extensions), (2) the VeriSign Global Registry Services ("VGRS") proposal, (3) the reassignment of the ".org" domain from its legacy provider to a new provider, and (4) the proposal to reform the ICANN management structure. We chose these topics for a variety of reasons, which include the relative interest shown by the Internet user community in their outcome (as demonstrated by the number and seriousness of the public comments), and because these topics represent four types of decisions that ICANN periodically makes in fulfilling its mandate of technical governance.

This review's bottom line is that the tenor of public commentary regarding a proposal before the board does not correlate strongly to an outcome either for or against that proposal. In several of the instances that we reviewed, the board voted against the position adopted by the majority of users who commented. Other types of input to the board, such as the recommendation of a relevant Supporting Organization or of a hired technical reviewer, correlate more strongly to the board's ultimate decision.

\footnotetext{
162. Critics of the methodology involved in this research point to this data set as the wrong place to look for the answers to questions about public participation in ICANN. To some extent, this critique is right on: there are many means of public participation in ICANN, and the public mailing lists and online discussion forums are among the least important compared to, for instance, the Supporting Organizations. These data are analyzed here because they are reliable and can be quantified, as compared to public inputs through the Supporting Organizations, which are less direct, and much harder to analyze. The fact that more than 100,000 posts have been published by thousands of Internet users around the world represents at least some effort on the part of the posters to engage in the ICANN decision-making process. For a formal rebuttal of this study, see Andrew McLaughlin, The Virtues of Deliberative Policymaking: A Response to "Public Participation in ICANN" (Dec. 17, 2003), at http://cyber.law.harvard.edu/mclaughlin/ mclaughlin -response-publicparticipation.html.
} 
First, we considered the process for introduction of new gTLDs in $2000 .{ }^{163}$ ICANN's initial introduction of new gTLDs was eagerly awaited and hotly contested, as forty-seven applicants submitted proposals for new gTLDs. ${ }^{164}$ There were two classes of gTLD proposals: those that were uncontested, in which only one pplicant sought a given new gTLD, and those that were contested, in which more than one applicant sought a given new gTLD. In each instance, the proposed new gTLD was evaluated via a threshold review to sort out those proposals that met initial technical and financial requirements. One of those criteria was public comment. ICANN's board considered each proposal against a series of criteria, ultimately choosing seven new gTLDs. In some cases, new gTLDs chosen had substantially more favorable than negative public commentary, as in the case of the ".coop" gTLD. In others, such as the contested ".biz" consideration, ICANN's board chose the only proposal, that of JV Team LLC (now NeuLevel), with more negative than positive public commentary. Some proposals that met the threshold review and received more positive than negative commentary from the public (e.g., "dir" and ".geo") were not chosen as new gTLDs. Finally, certain proposals with substantially more positive public commentary than negative commentary, but which did not meet the threshold standards, such as "llaw," were not chosen as new gTLDs. No particular pattern of support or non-support based on public commentary emerges from these data.

Second, we analyzed the process by which ICANN considered VeriSign's proposal for a new wait-listing service. ${ }^{165}$ During a special meeting of the board on August 23, 2002, ICANN voted to implement the VGRS. The public commentary was overwhelmingly opposed to the introduction of the wait-listing service. The Names Council, adopting a report developed by the Domain Names Supporting Oganization ("DNSO") Transfers Task Force, also recommended against this proposal. ${ }^{166}$ ICANN's general counsel mentioned that certain legitimate business interests might be endangered if the VGRS wait-listing service proposal were adopted, but did not directly oppose the proposal. Despite the strong objections expressed by those who

163. See generally ICANN, Top-Level Domains (gTLDs), at http://www.icann.org/tlds (last modified Dec. 16, 2003); ICANN, New TLD Program Application Archive, at http://www.icann.org/tlds/app-index.htm (last updated Nov. 27, 2000).

164. ICANN's second round of new gTLDs began in 2003. See [council] New gTLDs Committee - Timeline (Feb. 3, 2003), at http://does-not-exist.org/mail-archives/council/ $\mathrm{msg} 00375 . \mathrm{html}$ rendering the review of the first round particularly relevant.

165. See VeriSign Global Registry Servs., DOMAIN NAME WAIT LISTING SERVICE (Mar. 20, 2002), at http://www.icann.org/bucharest/ vgrs-wls-proposal-20mar02.pdf .

166. DOMAIN NAMES SUPPORTING ORG., FINAL REPORT OF THE TRANSFER TASK FORCE ON THE WLS PROPOSAL (July 14, 2002), at http://www.dnso.org/dnso/notes/ 20020714.TFtransfer-WLS-report.html 
submitted public commentary and the opposition of the Names Council and the DNSO Transfers Task Force, the ICANN board passed the VGRS waiting-list service proposal.

Third, we reviewed ICANN's reassignment of the ".org" domain from VeriSign to a new operator. ${ }^{167}$ On October 14, 2002, the ICANN board approved a proposal from the Internet Society to succeed VeriSign as operator of the ".org" domain. ${ }^{168}$ On this topic, the ICANN board sought input from four recognized groups ${ }^{169}$ who contributed to the staff evaluation of eleven applicants. The Internet Society received strong reviews from these recognized groups. The public commentary, which was relatively sparse, favored IMS/ISC, an applicant that failed. IMS/ISC did not meet the technical requirements set forth by Gartner. The Internet Society received more positive than negative comments, but at a less favorable ratio than IMS/ISC. In this instance, the public comments may have played a minor role in the board's choice of Internet Society as successor for the .org domain, but the anemic level of public participation ${ }^{170}$ meant that the technical advice of Gartner likely had the largest impact on the board's decision.

Finally, we considered the proposal to reform ICANN's structure in 2002. This reform process began in earnest when then-President Lynn published his Case for Reform ${ }^{171}$ in February 2002 and continued through the publication of a Blueprint for Reform, ${ }^{172}$ which sum-

167. See Materials on “.org” Reassignment, at http://www.icann.org/tlds/org/ (last updated Jan. 9, 2003).

168. See id.

169. See ICANN, Preliminary Report: Special Meeting of the Board (Oct. 14, 2002), at http://www.icann.org/minutes/prelim-report-4oct02.htm\#SuccessorOperatorfororgRegistry.

The four groups were: Gartner Inc., a U.S.-based technology consultant, which evaluated each bidder's proposal along technical lines; Non Commercial Domain Name Holders Constituency ("NCDNHC"), which considered "usage" criteria; ICANN's general counsel, which considered legal and policy implications; and the Academic CIO Evaluation Team, which also considered technical criteria. See GARTNER, INC., .ORG REASSIGNMENT-RFP REVIEW (Sept. 19, 2002), at http://www.icann.org/tlds/org/ gartner-evaluation-report-19aug02.pdf; NONCOMMERCIAL DOMAIN NAME HOLDERS CONSTITUENCY, .ORG DivestiTURE EVALUATION OF CRITERIA 4, 5 \& 6 (Sept. 9, 2002), at http://www.icann.org/tlds/org/ncdnhc-evaluation-report-09sep02.pdf; LOUIS TOUTON, .ORG REASSIGNMENT: GENERAL COUNSEL'S REPORT ON PROPOSALS FOR REASSIGNMENT OF THE .ORG REGISTRY (Sept. 22, 2002), at http://www.icann.org/tlds/org/general-counsels-report-22sep02.htm; ACADEMIC CIO EVAlUATION TEAM, .ORG REASSIGNMENT: ACADEMIC CIO TEAM EVALUATION UNDER TECHNICAL CRITERIA (\#1, \#7, \#8, and \#9) (Aug. 16, 2002), at http://www.icann.org/tlds/org/academic-cio-evaluation-report-19aug02.htm.

170. See supra note 159.

171. See LYNN, supra note 131.

172. See COMM. ON ICANN EVOLUTION \& REFORM, ICANN: A BLUEPRINT FOR REFORM (June 20, 2002), at http://www.icann.org/committees/evol-reform/ blueprint-20jun02.htm [hereinafter BLUEPRINT FOR REFORM]. 
marized the findings of the Evolution and Reform Committee. ${ }^{173}$ While there was no single board vote in favor of or against any single element of reform, ICANN has moved roughly in the direction of Lynn's proposal. However, throughout the reform process, the public commentary has been almost universally opposed to Lynn's suggestions and the reforms that the board has implemented. They have been particularly opposed to the move away from an At-Large Membership toward a less-direct method of public participation in choosing board members. Much of this opposition has expressed anger at ICANN's abandonment of all elements of representative democracy. The AtLarge Advisory Committee (chaired by Esther Dyson), which was designed to represent the user community, submitted a final report that recommended changes quite similar to the Lynn proposals. There is no evidence that the board has drectly taken the Internet user community's input into consideration throughout this ongoing reform process.

Our review of the Internet community's input through the public commentary process is not the only consideration of this general topic. A study by Professor Ethan Katsch and Dr. Alan Gaitenby, researchers at the University of Massachusetts, focused on the specific ICANN process called the Request for Reconsideration. ${ }^{174}$ This policy allows that "[a]ny person affected by an action of the [ICANN] may request review or reconsideration of that action by the board of Directors." ${ }^{175}$ Katsch and Gaitenby concluded, "If there are problems with the process, the problem is more with ICANN than with any users of the process." ${ }^{, 176}$ ICANN responded to twenty-six Requests for Reconsideration with formal decisions, rejecting all but one. ${ }^{177}$

Our review of the correlation between public input and board decisions is neither a complete study - as there is much more data that could be considered, particularly with respect to the Supporting Organizations - nor a statement about whether the board reached a sound decision on any given matter. The board may in fact have reached the right decision to fulfill its narrow technical mission in every instance, which would constitute success in the Raymond-style conception of openness. The same might be said of ICANN's decisions in the Request for Reconsideration process. However, even if ICANN made the right decision in every instance, it still loses legit imacy of authority with every decision, because it based its legitimacy on openness and representation and has failed to live up to these prin-

173. ETHAN KATSH \& AlAN GAITENBY, ThreE YeARS OF EXPERIENCE : A REPORT ON ICANN'S "REQUEST FOR CONSIDERATION" POLICY (June 25, 2002), at http://www.ombuds.org/reconsideration.

174. See id.

175. Id.

176. Id.

177. See id. 
ciples, at least if we construe them strictly. Given the rhetoric of its founders and current leadership, ICANN must confront the frustration felt by the Internet community when they do not feel heard, despite assurances to the contrary. ${ }^{178}$

\section{THE FAILURE OF ICANN'S EXPERIMENT IN REPRESENTATION}

When it became apparent that ICANN's experiment in openness was failing, ICANN shifted its focus to representation in an attempt to salvage its legitimacy of authority. With the Election of 2000, ICANN made a move toward becoming a more formally representative body. However, this approach failed spectacularly. Instead of making ICANN into a representative government entity, it made ICANN into a semidemocracy. Its semidemocratic form not only failed to address ICANN's problem of legitimacy, it also brought along a host of its own problems.

\section{A. The Election of 2000}

This one-time election was one manifestation of the struggle among ICANN's participants to craft the answers to the thorny questions regarding ICANN's legitimacy. The lack of clarity about ICANN's structure and the source of its authority offers room for those with an agenda to impose it on the organization. The group that championed the At-Large Membership and elected directors was one of the most vocal groups of ICANN participants. ${ }^{179}$ Many members of this group are individual technologists or Internet users; some members also work for large corporations, NGOs, or other powerful entities.

The activities of the former At-Large Membership and premise behind the Elections of 2000 are largely consistent with the overall goals and principles of ICANN, particularly with the goal of representation. ${ }^{180}$ Any person with Internet access who wished to become a member had the opportunity to do so during an open enrollment period by accessing the ICANN website and submitting a short form. ${ }^{181}$

178. See, e.g., Richard Henderson, ICANN and the Almost Invisible New TLD Evaluation Process, CIRCLEID NETWORK (Oct. 13, 2003), at http://www.circleid.com/print/320_0_1_0 (voicing user frustration about the lack of responsiveness to concerns regarding the secondround process for extending new top-level domains).

179. See, e.g., ICANN Watch, at http://www.icannwatch.org (last visited Feb. 19, 2004).

180. See Mats A. Palmgren, ICANN: Too Open and Too Closed?, WIRED.COM (Mar. 9, 2000), at http://www.wired.com/news/politics/0,1283,34882,00.html

181. The open enrollment program for the Election of 2000 ran from February 25 until July 31 of 2000. See ICANN, Rules for 2000 At Large Director Selection Process, at http://members.icann.org/rules.html(last visited Feb. 20, 2004). 
Instructions were translated from English into Chinese, Japanese, French, German, Korean, Portuguese, and Spanish. ICANN then mailed a letter to the registrant's physical address to verify that each member existed as a discrete individual. The letters included PIN numbers that could be used prior to September 8, 2000, to activate membership and voting rights. ${ }^{182}$ Those who registered then had the right to vote in a global, online election to select members to the board of directors. Candidates could nominate themselves prior to an August 14, 2000, deadline. Once nominated, they needed to secure not only support from residents of two or more countries, but also the support of twenty individuals, or two percent of the At-Large Members in his or her geographic region (whichever was greater). In October 2000, five directors were elected from distinct geographic regions (Africa, Asia and Pacific, Europe, Latin America and the Caribbean, and North America). These five directors served on the nineteenmember board, with full and equal powers relative to other board members, until their terms ended on December 15, 2002. The AtLarge Membership process was intended to make ICANN more representative by enabling any person who uses the Internet to have a formal voice in the management of ICANN. ${ }^{183}$ The Election of 2000 used an online interface and an Instant Runoff Voting system, using Election.com technology. ${ }^{184}$

The mechanics of registering voters, running the nomination and campaign period, as well as the actual election, went more or less smoothly, though some voters experienced frustrations in the process. ${ }^{185}$ During the registration period, some would-be members experienced difficulties in accessing the ICANN server and using their mailed PINs. ${ }^{186}$ At the time of the voting, " A few of the more than 76,000 at-large members discovered their online votes were not being accepted by the online voting booth,' said ICANN's Chief Policy Officer Andrew McLaughlin." ${ }^{187}$ Contemporary reports suggested that about 400 members may have been affected by this difficulty. ${ }^{188}$ It is unclear, however, if any of these voters then decided not to vote or in

182. See About ICANN's At Large Membership Program, supra note 15.

183. See generally ICANN, At Large Membership and Elections, at http://www.icann.org/committees/at -large/at-large.htm (last visited Feb. 29, 2003).

184. See Ctr. for Voting \& Democracy, ICANN to Use IRV for Worldwide Election of Board Members, at http://www.fairvote.org/irv/icann.htm (last visited Feb. 20, 2003).

185. See CARTER CTR. FOR ELECTION MONITORING, REPORT ON THE GLOBAL, ON-LINE, DiRECT EleCtions For Five SEATS REPRESENTING AT-LARGE MEMBERS ON THE BOARD OF DIRECTORS OF THE INTERNET CORPORATION FOR ASSIGNED NAMES AND NUMBERS (ICANN), at http://www.markle.org/News/Icann2_Report.Pdf (last visited Feb. 7, 2004) (giving a comprehensive review of the mechanics of the ICANN Election of 2000).

186. See Press Release, Carter Center, Carter Center Representatives Observe ICANN Balloting (Oct. 11, 2000), at http://members.icann.org/carter.htm.

187. James Evans, ICANN Election Starts with Small Snag, INFO WORLD DAILY NEWS, Oct. 2, 2000.

188. See id. 
fact returned later to submit their ballots. These mechanical problems, while necessary to be addressed in future Internet-based elections, do not appear so serious as to suggest that global online elections are unfeasible. ${ }^{189}$

The At-Large Membership drive and Election of 2000 were deemed a success by ICANN staff and by some observers at the time of their completion. ${ }^{190}$ "With over 76,000 activated members," the

ICANN site proclaims, "ICANN achieved its goal of a large, globally diverse membership." ${ }^{\prime 91}$ Of the 158,000 people who signed up for AtLarge Membership online during the summer of 2000, 76,000 persons activated their membership and established voting rights. Of hose eligible to vote, 34,035 cast valid ballots. ${ }^{192}$ Those voters represented a $45 \%$ turnout of those eligible and a $22 \%$ turnout of those who initiated the registration process. Of the world's estimated 375 million Internet users at the time, less than 0.01 percent voted in the ICANN Election of 2000, with only 130 ballots cast from the continent of Africa. ${ }^{193}$

The Election of 2000 resulted in the ascendancy to the ICANN board of five individuals from the five geographic regions, as promised, to fill just over one quarter of the ICANN board seats. Nii Quaynor of Ghana won with 67 of the 130 ballots cast from the Africa region. ${ }^{194}$ Masanobu Katoh of Japan won with 13,913 of the 17,745 votes cast from the Asia / Australia / Pacific region. ${ }^{195}$ Andy MuellerMaguhn of Germany won with 5,948 of the 11,309 votes cast in Europe. ${ }^{196}$ Ivan Moura Campos of Brazil won with 946 of 1,402 ballots cast in the Latin American / Caribbean region. ${ }^{197}$ Karl Auerbach of the United States won with 1,074 of the 3,449 votes cast in North America. ${ }^{198}$ These representatives of the At-Large Membership played an active role in ICANN's management after their election,

189. But see MICHAEL M. ROBERTS, TOWARDS IMPROVED REPRESENTATION IN ICANN (Aug. 10, 2001), at http://www.atlargestudy.org/roberts_paper.html

190. See, e.g., Press Release, Markle Foundation, ICANN Elections: An Important Mbment for Internet Governance (Oct. 11, 2000), at http:/www.markle.org/news/ _news_pressrelease_101100.stm.

191. ICANN, ICANN At Large Membership, at http://members.icann.org/index.html (last visited Feb. 7, 2004).

192. These figures have been validated independently by the Carter Center, which observed the online election. See CARTER CTR., supra note 185.

193. See Press Release, eTForecasts, Worldwide Internet Users Will Reach 375M in 2000 (May 1, 2000), at http://www.etforecasts.com/pr/pr500.htm.

194. All results come from a special section of the Election.com website reserved for the ICANN Election of 2000. See Results of the 2000 At Large Membership Vote, at http://www.election.com/us/icann/icannresult.html(last visited Feb. 21, 2004).

195. Id.

196. Id.

197. Id.

198. Id. 
including vocal participation at ICANN board meetings. ${ }^{199}$ Two of these directors, Auerbach and Mueller-Maguhn, had longstanding records as outspoken critics of ICANN's management prior to their election to the board. ${ }^{200}$

Both ICANN itself and outside organizations conducted formal studies of the Election of 2000 and of the At-Large Membership. The two most important of these studies - ICANN's own At-Large Membership report, and a report led by academics and the Center for Democracy and Technology, an NGO in Washington, D.C. - reached markedly different conclusions about what the election experiment suggested for ICANN's future. ${ }^{201}$ ICANN announced an At-Large Membership Study Committee on January 26, 2001, ${ }^{202}$ with a goal of reporting back to the board of ICANN in November $2001 .^{203}$ ICANN planned a formal two-year review to consider the propriety of the AtLarge Membership, but this was roundly criticized as too slow and as potentially undercutting the At-Large Membership itself; the latter critique proved accurate. ${ }^{204}$ The Center for Democracy and Technology, also has conducted a study in collaboration with Common Cause, a well-respected NGO based in the United States. ${ }^{205}$ These studies, however, managed neither to address the core issues of representation within ICANN, nor to clarify the meaning of "representation" within the ICANN structure.

199. A review of the scribe's notes of board meetings between 2000 and 2003, posted on the Berkman Center's website, will give a sense of this dynamic. See Berkman Center ICANN-Related Content Archive, at http://cyber.law.harvard.edu/icann (last visited Feb. 21, 2004).

200. Examples of Mueller-Maguhn and Auerbach's criticism of ICANN are legion. The scribe's notes of the March 2001 board meeting in Melbourne, Australia, will reveal some of the issues that caused them concern. See ICANN Public Meetings: Remote Participation and Archives, at http://cyber.law.harvard.edu/icann/melbourne (last visited Feb. 7, 2004); see also Declan McCullagh, ICANN Elects Iconoclasts, WIRED.COM (Oct. 12, 2000), at http://www.wired.com/news/politics/0,1283,39385,00.html; Yedidya M. Melchior, ICANN Elections, MishPAT CYBERLAW INFORMER, at $\S 3$ (Oct. 15, 2000), at http://mishpat.net/ cyberlaw/archive/cyberlaw59.shtml

201. Compare FinAl REPORT ON ICANN AT LARGE MEMBERSHIP supra note 16, with NGO \& ACADEMIC ICANN STUDY, supra note 16.

202. Press Release, ICANN, ICANN Launches At Large Membership Study - Carl Bildt to Chair Study Committee (Jan. 26, 2001), at http://www.icann.org/ announcements/icann-pr26jan01.htm; see also Charter of the At Large Study Committee (Jan. 22, 2001), at http://www.icann.org/committees/at-large-study/charter-22jan01.htm. See generally At-Large Study Comm., About the ALSC, at http://www.atlargestudy.org (last visited Feb. 13, 2004) (describing background information regarding the At-Large Study Committee)

203. At-Large Advisory Comm., About the ALAC, at http://www.atlargestudy.org/ about.shtml (last visited Mar. 16, 2004) ("The Committee plans to submit final recommendations to ICANN's Board in November of this year.").

204. See David McGuire, ICANN Board Member Rips At-Large Membership Study, NEWSBYTES NEWS NETWORK (Feb. 2, 2001), at http://www.findarticles.com/cf_dls/ m0NEW/2001_Feb_2/69970352/p1/article.jhtml (describing Karl Auerbach's reaction).

205. See BERMAN, supra note 115. 
On some level, the ICANN Election of 2000 was historic. A sui generis, not-for-profit corporation held elections for five board members in which 76,000 people from most parts of the globe participated using Internet-based technology. ${ }^{206}$ Those who organized the election were conscious of its potential historical place. "The At Large Members of ICANN will be participating in a historic first - a worldwide online election to choose Directors for the Internet's private-sector technical coordinating body." 207 ICANN's feat is remarkable on its face. ${ }^{208}$ ICANN's election of five of nineteen directors, with a goal of creating a representative organization, however, is unsettling when considered from the perspective of political theory.

\section{B. Why ICANN's Semidemocratic Structure Was Doomed to Fail}

The combination of ICANN's curious structure and its unconvincing attempts in representing the global Internet community has left ICANN in the awkward, unsustainable position of a semidemocracy. ICANN's semidemocratic structure poses serious problems for the organization over the long term. These problems could include capture by powerful interests, directors who do not represent the Internet community at large, a disengaged user community, and difficult transition periods. Finally, its semidemocratic structure has left ICANN without a solution to its problem of legitimacy.

\section{ICANN as a Semidemocracy}

In the wake of the Election of 2000, ICANN's mixed board of directors - with five elected and fourteen non-elected directors placed the organization into the nebulous zone occupied by semidemocracies, partway between the authoritarian and pluralistic models of governance. Even without the directly elected directors, ICANN's hybrid structure is semidemocratic. This authoritarian-pluralist model is characterized by a situation in which "the party or other governing group retains a monopoly on political power but is willing to grant a measure of political and cultural freedom at the individual, group, and

206. But see MUELLER, supra note 24, 217-18 (arguing that ICANN is not be st seen as a sui generis institution).

207. About ICANN's At Large Membership Program, supra note 15.

208. But see Scribe's Notes: ICANN Board Meeting, Yokohama, Japan (July 16, 2000), at http://cyber.law.harvard.edu/icann/yokohama/archive/scribe-icann-071600.html (quoting ICANN then-CEO Mike Roberts's statement downplaying the Election's significance: "Well-meaning people all over the world are mistakenly calling this a 'global election' and not noticing that we're a small company with a limited mission."). It is interesting to note this mixed rhetoric from ICANN; its role is at once limited and historic. See About ICANN's At-Large Membership Program, supra note 15. This contradictory rhetoric suggests a deep ambivalence about ICANN's mission that may have serious and complex implications. 
regional levels." ${ }^{209}$ One way to retell the story of ICANN's development is that the non-elected board members (and those chosen by the Supporting Organizations) continued to retain all political power. Although they temporarily acceded to the user community's demands for directly elected board members, they then removed those directors after only a single term. ${ }^{210}$

The semidemocratic model fits ICANN particularly well, not just in light of the Election of 2000, but also from the perspective of ICANN's corporate form. The board of directors retains absolute control over the decision-making process (or "monopoly power" in the sense that a political scientist uses the term). However, the board has the flexibility to grant the managers and other stakeholders, such as the Supporting Organizations, the freedom to act. For instance, the board delegates certain spending powers which allow the managers independently to authorize expenditures, similar to how an ordinary corporate or non-profit board would empower its managers. The staff and outside counsel can negotiate on behalf of the board with key partners, such as VeriSign, and present agreements to the board for consideration, discussion, and subsequent approval, as they did at the Melbourne board meeting in March 2001. ${ }^{211}$ Supporting Organizations are also empowered to make recommendations to the board. ${ }^{212}$ This at least suggests the possibility that parties other than the board and staff members are participating in the governance process.

One take on the Election of 2000 and its aftermath is that ICANN should be lauded for its move toward semidemocracy. Those who believe that direct representation is the best structure for ICANN viewed the Election of 2000 as a first step in the right direction. The

209. Muthiah Alagappa, The Asian Spectrum, J. DEMOCRACY, Jan. 1995, at 29, 33.

210. It is important to distinguish among at least three classes of ICANN directors: those chosen initially in 1998 (likely by Dr. Jon Postel), those sent to the board by the Supporting Organizations, and those elected by the At-Large Membership in the fall of 2001. This critique of ICANN is not intended to suggest that any class of directors, or any individual director, is inherently bad, but rather to point to the complexities and possible problems caused by ICANN's hybrid structure and divergent sources of authority among these classes. For instance, if one could conclude that the Supporting Organizations achieved global representation of the Internet community and subsequently established fair, open, and regular election practices, there is no inherent reason to suggest that this model should not be used to elect ICANN directors. One very clear reason to support a Supporting Organization-elected board could be to ensure that the technical community is looking after what is ultimately a technical process. But there is no reason to believe that the Supporting Organizations inherently represent the technical community, much less the broader global Internet community; the required sources of authority and legitimacy for the Supporting Organization have not been clearly established.

211. This description is not intended to imply that the ICANN staff presents an up-ordown proposal that the board must decide upon immediately. As in most corporations, the board has the opportunity to discuss proposals, ask for additional input and advice, propose changes, table proposals, and act on them at its collective discretion.

212. ICANN BYLAWS (effective Nov. 21, 1998), available at http://www.icann.org/ general/archive-bylaws/bylaws-23nov98.htm. 
logical progression would be for ICANN to gravitate from a fully appointed board to a fully elected board. In this progression, the Election of 2000 would be followed by a subsequent election to bring the next four elected members onto the board. After that experiment has proven itself a success, ICANN might move towards electing all its board members via the At-Large Membership. ICANN could capitalize on the success of its most recent election to build greater legit imacy across the globe through a model of deliberation and inclusion. ${ }^{213}$ ICANN would thus be empowering the Internet user community to partic ipate in the governance process. This incremental and hopeful view, however, is unconvincing in light of historical experiences with semidemocracies; it is also highly unlikely at this point that ICANN will, or should, move toward a purely democratic model. ${ }^{214}$

From the other end of the spectrum, the harshest criticism of the Election of 2000 posits that ICANN's move toward semidemocracy is nothing more than an instance of "placative politics." 215 The ICANN board, the theory goes, has sustained so much criticism from a vocal opposition in the press, on the Web, and in meetings that it sought a means of placating the user community. The most obvious means is to enable the user community to elect representatives to the board who, even when voting in a bloc, cannot effect change within the institution. The sole aim of such an election process is to placate the vocal critics - perhaps even landing some such critics in positions of nominal authority - with no intention of ceding any real power to the user community. Potentially, once the elected representatives behave poorly, or interest in electing powerless representatives wanes, the board can revert to its pure non-elected form. ${ }^{216}$ Even without fully reverting to a non-elected board, the placative approach might manage to squelch public interest in ICANN. In Professor Roberto Unger's terms, placative politics involve "the adoption of rules and practices maintaining society at a relatively low level of political mobilization," with the goal of securing "property against populism."217 A number of

213. See Seyla Benhabib, Toward a Deliberative Model of Democratic Legitimacy, in DEMOCRACY AND DIFFERENCE: CONTESTING THE BOUNDARIES OF THE POLITICAL 67-94 (Seyla Benhabib ed., 1996).

214. See discussion infra Section V.A.

215. "Placative politics" is intended to convey a political modus operandi that aims mainly to placate, but not necessarily to empower, those with a stake in the outcome under consideration. This notion was developed during a series of conversations with Professor Jonathan Zittrain.

216. Again, one must consider whether the representatives of the Supporting Organizations are properly thought of as "representing" anyone. To the extent that the Supporting Organizations continue to send members to the board, the semidemocratic structure arguably remains intact, even absent the directly elected representatives.

217. Roberto M. Unger, Democracy Realized: The Progressive Alternative 264 (1998). 
ICANN critic s, fearing a similar lack of commitment from the board toward moving further in the direction of direct representation, called for the immediate resignation of the board's "squatters" and for the election of the next four board members through the At-Large Membership system. ${ }^{218}$

The political history of the second half of the twentieth century suggests that either model could be right. ${ }^{219}$ Those who think in terms of U.S. and democratic triumphalism tend to think of semidemocracies as mere way stations between authoritarian or totalitarian regimes and the ultimate end-state of representative democracies. History offers a few such transitions of various completeness, including but not limited to a number of Eastern European states and certain countries in South America in the late twentieth century. ${ }^{220}$ Of these examples, Chile and Brazil may serve as the best examples of the gradual transition through semidemocracy toward an ultimately democratic regime. ${ }^{221}$ South Africa over the past decade presents a particularly graphic example, though with a spin on the same notion of transition. In South Africa, the change took the form of a fairly abrupt movement from exclusion to inclusion of racial minorities, rather than a gradual transition from autocratic to democratic structures. ${ }^{222}$ In contrast, examples from East Asia, such as Malaysia and Singapore, may lead to the conclusion that semidemocracy is a final or semi-permanent stage rather than merely a phase in a long-term trans ition. ${ }^{223}$

218. See A. Michael Froomkin, Beware the ICANN Board Squatters (Oct. 27, 2000), at http://personal.law.miami.edu/ froomkin/boardsquat.htm; A. Michael Froomkin, Replacing the ICANN Board Squatters (Nov. 9, 2000), at http://personal.law.miami.edu/ froomkin/boardsquat2.htm; see also David McGuire, ICANN Antagonist Calls for Board Resignations, NEWSBYTES NEWS NETWORK (Oct. 30, 2000), at http://www.computeruser.com/news/00/10/30/news8.html; Press Release, ICANN, ICANN Announces Names of Directors to Serve Extended Terms, at http://www.icann.org/ announcements/icann-pr27oct00.htm (last visited Jan. 29, 2003) (announcing the apparently arbitrary extension of four of the directors' terms into 2002 rather than having those directors resign and be elected by the At-Large Membership).

219. See generally PAUL BROOKER, NON DEMOCRATIC REGIMES: THEORY, GOVERNMENT ANDPOLITICS (2000).

220. See generally CONSTITUTIONALISM IN TRANSFORMATION: EUROPEAN AND THEORETICAL PERSPECTIVES (Richard Bellamy \& Dario Castiglione eds., 1996).

221. Andreas Schedler, Concepts of Democratic Consolidation (Apr. 19, 1997), at http://136.142.158.105/LASA97/schedler.pdf. See generally UNGER, supra note 217; ELISABETH J. WOOD, FORGING DEMOCRACY FROM BELOW: INSURGENT TRANSITIONS IN SOUTH AFRICA ANDEL SALVADOR (2000).

222. See generally Timothy D. SiSK, DEMOCRATIZATION IN SOUTH AFrica: THE ELUSIVE SOCIAL CONTRACT (1995); WOOD, supra note 221.

223. I find it hard to analogize further between ICANN and these political historical examples, in part because it is a challenge to know whether ICANN is headed toward or away from a democratic model. When the first five directly elected representatives of the At Large Membership joined the board, one might have made an argument that ICANN was inclining away from an authoritarian model and towards a democratic model. Since the end of the At-Large Election experiment, it appears as though ICANN is zigzagging in precisely the opposite direction. One of the central themes of this paper is that ICANN should stop 
The effort to apply the political histories of modern nation-states to the study of ICANN is fraught with problems and is ultimately inconclusive. The difficulty of using case studies of this sort traces back to the fact that the parallel between ICANN and a nation-state is imperfect. ICANN is a new institution, and potentially a new kind of institution, filling a perplexing new void rather than replacing an old institution with a new one. ${ }^{224}$ Even if the parallels hold up under scrutiny, examples from political history present an unclear conclusion as to whether semidemocracies are way stations or endpoints. The period between the Election of 2000 and the end of the elected directors' terms at the close of 2002, however, has seen a pull-back away from the expansion of democratic decision making, not a continued push in the pro-democratic direction. ICANN itself is rapidly becoming an example of the perils of the semidemocratic structure.

\section{Problems Facing ICANN as a Semidemocracy}

If the most recent statement from the U.S. Department of Commerce when renewing its MoU with ICANN is to be believed, ICANN likely will not undertake radical reform of its structure, but rather persist with some variant of its hybrid form. ${ }^{225}$ From the perspective of political theory, such persistence may not be a good idea. Politic al theory offers a picture with less ambiguity than political history and provides support for the harsher and less promising view of ICANN's semidemocratic, hybrid structure. ICANN's particular semidemocratic structure may have led, and may continue to lead, to problems that can be categorized into two tiers of concerns. The firsttier concern - capture without recourse - seems to be the most likely and the most worrisome outcome, while second-tier concerns are worth noting but present less likely and less severe potential problems.

\section{a. The First-Tier Concern: Capture Without Recourse}

The fear of capture is the most prevalent concern for any organizational structure without strong democratic safeguards or other ob-

careening and start again from the beginning by establishing new principles, determining a defensible source of authority, and adopting a structure that suits its mandate.

224. One might argue that the parallel between states in transition and ICANN has merit, given that many of these insurgencies are viewed as popular uprisings against entrenched economic interests. This mirrors the rise of the At-Large Membership, which can be seen as the Internet community striking back against the entrenched economic interests of the registries, registrars, and other Internet corporate interests.

225. See Statement Regarding MoU, supra note 5 (suggesting that ICANN ought to continue to seek reform, but also "complete the transition of DNS management to the private sector"). 
vious methods of checks and balances. ${ }^{226}$ A semidemocratic regime, in which the broad community may not affect policy even if they act as a single voting bloc, is inherently subject to capture. Without effective and reliable means of replacing the organization's leaders if they do not act in the best interests of the broader community, the semidemocratic structure affords no recourse in the event of capture. In ICANN's case, the board of directors may or may not have adequately represented the interests of the global Internet community. Whether or not the board has achieved representation with a minority of elected directors is irrelevant for this analysis; in the event that the board does not positively represent the Internet community, the community has no effective means of replacing those directors. ${ }^{227}$ The only recourse available to the Internet community would be self-help. The Internet community could work around ICANN, either by building an alternative network or by ignoring its allegedly illegitimate authority. ${ }^{228}$

This fear of capture is ordinarily expressed in terms of corporate interests - or the loosely defined intellectual property constituency at large - taking control of the institution, leaving the broader community without recourse. Corporations, both based in the United States and abroad, have demonstrated their serious interest in ICANN. ICANN's financial statements for the six-month period ending in December 2000 revealed that the ICANN corporation's creditors include heavyweights Cisco Systems, Inc., Deutsche Telekom AG, Inc., MCI Worldcom, Inc., and 3COM. ${ }^{229}$ Several board members, including

226. Professor David Post describes this fear of capture without recourse in the language of checks and balances found in U.S. -style constitutional parlance. "Who wields this power, and what keeps them from exercising it arbitrarily and oppressively — are questions of the deepest importance for the continued development of a vibrant Internet." Post, supra note 2. Post's comments have particular resonance because ICANN's semidemocratic structure has even fewer checks and balances than a traditional corporation. In the ordinary corporate form, if the directors act in a manner that is not considered to be in the best interests of the shareholders, the majority of shareholders have the ultimate recourse of voting the directors out of office. Likewise, under the administrative agency model, a process of judicial review provides such a check on the activities of the agency's officials. No such ult imate power resides in the broader community of ICANN's stakeholders, despite the founding documents' insistence that the organization functions in a manner that is representative of the global community of Internet users. The only plausible check resides in the U.S. Department of Commerce's ability to cut off its grant of authority through the MoU.

227. One might argue that the Supporting Organizations structure, or the new Nominating Committee arrangement, allows for the community to represent itself. However, such a route is far from certain and lacks complete transparency. Also, the notion of who belongs to the Internet community is a problem that has long plagued ICANN. For instance, do governments and corporate interests stand on the same footing as domain name holders or yet further removed, non-domain-name-holding Internet users?

228. The nascent challenge to ICANN presented by New.net, an alternative DNS initially backed by idealab! and others, might represent one such example of self-help. See Andy Patrizio, New.net Defies Domain System, WIRED.COM (Mar. 5, 2001), at http://www.wired.com/news/business/0,1367,42146,00.html.

229. See ICANN, 6-MONTH FINANCIAL REPORT FOR PERIOD ENDING 31 DECEMBER 2000 (Feb. 27, 2001), at http://www.icann.org/financials/financial-report-fpe-31dec00.htm. In addition to concerns about corporate control or capture of ICANN, this list of creditors 
chairman Vint Cerf and former At-Large board representative Karl Auerbach, have been employed by two of these creditors during their respective terms as directors. In addition to creditors who supported ICANN during its cash-poor infancy, registrars and registries are required by contract to make payments to ICANN. ${ }^{230}$ Also, the Registrars make payments up to $\$ 3.5$ million a year. ${ }^{231}$ In light of these corporate loans and payments, the ACLU has made its position clear that ICANN's structure presents a substantial risk of capture by corporate interests. ${ }^{232}$

Two counterarguments undercut, but fail to mitigate completely, the fear of capture posed by the semidemocratic structure. First, the Supporting Organization structure may help to prevent capture by any given constituency and to ensure user input into board decisionmaking. The Supporting Organizations have traditionally sent nine of the nineteen directors to the board. Within the Supporting Organizations, individual Internet users, academics, and others play a substantial role; through the Supporting Organizations, these arguably public spirited individuals may represent the community interest effectively when they elect directors and make potentially binding recommendations to the ICANN board. The new Nominating Committee process may assist in this fashion as well. However, while such individuals do participate in the ICANN governance system, there is no reason to believe either that they would have the ability to protect against capture, or that they would not be swayed to support those who would capture the organization. A second counterargument to the fear of capture centers on the fact that a semidemocracy is no more at risk of capture than any other authoritarian structure. While true on one level, the concern about semidemocracies and capture still stands. Moreover, the placative element of the semidemocratic structure may render participants less alert to the possibility of capture, potentially resulting in fewer measures designed to prevent the capture scenario.

\section{b. Second-Tier Concerns}

A series of secondary concerns regarding ICANN's semidemocratic structure include the costs and inefficiencies of such a structure; the reduced ability of the organization to adapt to changing circumstances; the tendency toward nepotism rather than merit-based promo-

also suggests that ICANN has historically been literally indebted to a group of exclusively Western, and almost exclusively U.S.-based, entities.

230. See Revised VeriSign Registry Agreement (Apr. 16, 2001), at http://www.icann.org/tlds/agreements/verisign.

231. See id.

232. See Letter from Barry Steinhardt, Associate Director of the ACLU, to Secretary Norman Mineta, U.S. Department of Commerce (Jan. 16, 2001), at http://www.aclu.org/ congress/1011601a.html. 
tion, which reduces the quality of key actors over time; a reduced ability to handle the inevitable periods of transition effectively; and, potentially, a lost opportunity problem. ${ }^{233}$

\section{i. Cost and Inefficiency}

ICANN's semidemocratic system brings with it a series of costs and few offsetting benefits. It is an essentially meaningless electoral system that costs ICANN the money that it paid to Election.com to outsource the election, ICANN's own staff time, and the opportunity costs of the time and money devoted by ICANN and its supporters to the election process. The process also risks demoralizing the community at large. ${ }^{234}$ While a $\$ 200,000$ grant from the Markle Foundation provided some support for the At-Large Membership election process, it did not cover all financial costs for tasks such as mailing 120,000 letters. ${ }^{235}$ The counterargument suggests that the cost to ICANN of running the At-Large Election is not great relative to its overall budget. However, the cost of enabling, but ignoring, public commentary, while unknowable, is certainly a non-zero amount. In the event that any cost to an organization with a public function is allocated to an activity that may have a net negative impact to the organization or to the public at large, such a cost is unjustified.

\section{ii. Less Effective Reaction to Change}

ICANN's semidemocratic structure may result in its management being less responsive to the need for change than a counterpart $\alpha$ ganization with an effective representative mechanism. In the short term, semidemocracies fail to incorporate the need for change into real-time policy-making, as the lines of communication between the governed and the governors get pinched and become plagued by

233. There are other concerns about semidemocracies that are not discussed in this Art icle. One important concern is the argument that complex forms tend to be less stable than pure forms of governance, but the empirical evidence is unclear. See, e.g., Marc Stier, Is Democracy Stable? Compared to What?: A Preliminary Expbration, at http://www.stier.net/writing/demstab/demstab.htm (last visited Mar. 18, 2004).

234. The sense of demoralization implied here is a variant of Professor Frank Michelman's famous take on "demoralization costs" in the context of U.S. takings clause jurisprudence. See Frank I. Michelman, Property, Utility, and Fairness: Comments on the Ethical Foundations of “Just Compensation" Law, 80 HARV. L. REV. 1165, 1183-1201 (1967).

235. See ICANN, A Proposal to the Markle Foundation for Grant Support of ICANN's At Large Membership and Election Program (Oct. 21, 1999), at http://www.icann.org/committees/at-large/markle-proposal-21oct99.htm; see also Scribe's Notes: ICANN Public Forum Yokohama Japan (July 15, 2000), at http://cyber.law.harvard.edu/icann/yokohama/archive/scribe-icann-071500.html. 
static. ${ }^{236}$ In the long term, a semidemocracy is less able than authoritarian or democratic regimes to change its practices and its structure in needed ways to respond to changing times. ${ }^{237}$ Professor Unger suggests that certain forms of governance, which could include the semidemocracy, exhibit this shrunken transformative ability. ${ }^{238}$

This shrunken transformative ability could manifest itself in a number of potentially damaging ways for ICANN. Semidemocracies, for instance, have a hard time recovering from a decline in the perception of the organization's legitimacy of authority. ${ }^{239}$ In the event that the election process is believed to be meaningful, the leaders can hold a legitimate election to begin the process of restoring belief and trust in the system. Authoritarian leaders, by contrast, can act quickly to alter organizational structure by fiat or by making policy decisions to restore a belief in their legitimacy of authority. ${ }^{240}$ The leaders of the semidemocracy have at their disposal neither the surer path of the true democracy, nor the efficient path of the true authoritarian, to address a crisis of legitimacy. In light of the substantial policy changes that ICANN has made in its short history, thus far this concern of shrunken transformative ability does not seem to be acute for ICANN. ${ }^{241}$ However, if ICANN moves further away from the authoritarian model, this concern will become more pertinent.

\section{iii. Danger of Nepotistic, Rather Than Meritocratic, Promotion}

The promotion of new directors in a semidemocratic system is more likely to be based on nepotism than on merit-based consideration. ${ }^{242}$ ICANN's critics are particularly attuned to this danger given the organization's history. The initial members of the board were ap-

236. An organization like ICANN that extensively uses advanced information and communications technologies might be less prone to such a problem than less technologically inclined organizations.

237. But see Posting of Joe Sims, Joe_Sims@jonesday.com, to commentbylaws@icann.org (Oct. 23, 1999), at http://www.icann.org/comments-mail/ comment-bylaws/msg00025.html (arguing that ICANN may not want to be able to change quickly: "This objective [maintaining the stability of the DNS] requires slower, not faster, decision-making and incremental change.").

238. See UNGER, supra note 217, at 265.

239. See Alagappa, supra note 209.

240. See id. at 35 (discussing East and Southeast Asian authoritarian regimes which rely on economic development as a main source of their legitimacy).

241. Consider, for instance, the several versions of appointing board members over the past five years: from the initial "divine right of kings approach," to a process primarily involving the Supporting Organizations, to a semi-elected board, to a non-elected board, and finally to a revamped Nominating Committee procedure for those board members not nominated through the Supportin g Organization process. See ICANN, ICANN Nominating Committee, at http://www.icann.org/committees/nom-comm (last modified Dec. 5, 2003) (describing current system for appointment).

242. See Alexander A. Galkin, AUthoritarianism in RUSSia: Dangers For DEMOCRACY (1999), at http://www.nato.int/acad/fellow/97-99/galkin.pdf. 
pointed by one man, Jon Postel, or at most by a small group of insiders with a vested interest in the composition of the board. ${ }^{243}$ In a semidemocracy, the community at large has little or no recourse when nepotism is used to appoint people who do not act in the best interests of the community. A simple cost-benefit analysis suggests that the appointer may choose a leader based on allegiance if the potential benefits of future decisions outweigh the community's outrage. For ICANN, this may not be a severe problem. The track record of ICANN's appointments has been laudable, given the talent and commitment (albeit not perfect diversity) of the board's membership. ${ }^{24}$ Moreover, the structures of the supporting organizations may result in greater consideration of merit in the board appointment process. However, this concern remains valid to the extent that the ICANN structure provides few safeguards to prevent nepotistic rather than meritocratic promotion.

The relative homogeneity of leaders in a semidemocratic structure tracks this concern about nepotism holding the upper hand. One of the hallmarks of well-run democracies is the variety of leaders with different qualities who assume positions of influence. This diversity of strengths is less likely to be the case in semidemocracies or authoritarian regimes. For ICANN, this theoretical tendency toward homogeneity is in direct conflict with ICANN's mandate to represent the global community of Internet users. ${ }^{245}$ Diversity of ethnic, cultural, geographic, professional, or other backgrounds may result both in a better policy and a greater likelihood that the world's Internet users are truly being represented in ICANN. Given ICANN's global reach and founding principles, this inclination of semidemocracies against fostering such diversity should be taken seriously. ${ }^{246}$

\section{iv. Transitions Are Handled Clumsily}

Semidemocracies struggle with transitions. ICANN is no exception to that rule. Political scientists believe that democracies manage

243. Given the timing of Postel's death, it is almost certain that Joe Sims, the influential counsel to ICANN, played a significant role in the initial board's make-up.

244. Some ICANN critics complain that corporate interests are too well represented at the expense of the Internet user community. See, e.g., Reclaimthe.net, Is the ICANN \$50,000.00 TLD Applic ation Fee a Scam?, at http://reclaimthe.net/icann/scam/ (last visited Mar. 5, 2004).

245. One could argue that ICANN has done an admirable job of avoiding homogeneity. However, the point that I am making is theoretical rather than historical.

246. ICANN has faced a serious diversity problem since its founding. One prevalent critique of ICANN has been the dearth of involvement from people in developing countries. ICANN has made enormous efforts in this particular regard, led by Chief Policy Officer Andrew McLaughlin, who is an expert in information and communications technologies in developing nations. See Andrew McLaughlin, at http://cyber.law.harvard.edu/ mclaughlin.html (last visited Mar. 18, 2004). The recently -announced Nominating Commi tee process is meant in part to address this substantial concern. 
to achieve orderly, scheduled transitions better than semidemocracies or authoritarian regimes. ${ }^{247} \mathrm{~A}$ semidemocratic transition often involves a two-step by the existing leaders: to act open enough to appease those who seek involvement and openness, but also to act quickly and decisively enough to effect the necessary or desired transfer of power. In ICANN's case, this failure to make transitions promptly and elegantly has manifested itself in the organization's first several years of operation. For instance, after one or two years, the original appointed board was intended to be replaced by a board chosen half by the Supporting Organizations and half by the membership. ${ }^{248}$ However, three of the original board members remained on the board for over five years. ${ }^{249}$ The semidemocratic structure lends itself to more awkward transitions than its pure-structural counterparts. ICANN has shown no likelihood of overcoming the transitional problems of its semidemocratic structure, even as the December 15, 2002, board transition raised precisely these concerns.

\section{The Semidemocratic Structure Does Nothing to Address ICANN's Legitimacy of Authority Problem}

Even if none of political theory's predictions come to pass, a semidemocratic structure still hurts ICANN because it fails to address ICANN's most pressing problem: the public perception that ICANN lacks legitimacy of authority. ${ }^{250}$ A compelling articulation of an $\alpha$ ganization's legitimacy is critical for the organization's ability to carry out its mandate. ${ }^{251}$ ICANN's hybrid structure gives it none of the authority of its component parts: its formal top-down decision structure takes away the standards body's legitimacy through true openness, its corporate structure takes away the democrac y's legitimacy through true representation, and its principles of openness and representation take away the corporation's legitimacy through authority and efficiency. To the extent that ICANN's power flows from an agreement with the United States, ICANN will continue to face increasing difficulty in credibly asserting its authority in an international

247. One can profitably compare the transfer of power within a corporation to the transfer of power in a state. This analogy is particularly informative for ICANN, because in many ways ICANN operates like a state. See supra Section II.B.3.

248. See generally Froomkin, supra note 218 (discussing the board's failure to transfer power within a one- to two-year timeframe as originally anticipated).

249. The three original members who remained on the ICANN board until June 2003 are Hans Kraaijenbrink, Jun Murai, and Linda Wilson. See ICANN, Board of Directors, at http://www.icann.org/general/board.html (last modified Feb. 24, 2004).

250. See Weinberg, supra note 4, at 212-17.

251. See generally SAMUEL P. HunTINGTON, THE THIRD WAVE: DEMOCRATIZATION IN THE LATE TWENTIETH CENTURY (1991) (discussing the importance of legitimacy of authority within democratic states); ROUSSEAU, supra note 103, at 454-58 (describing the source of legitimacy of authority). 
context. To the extent that the authority flows from the Internet user community, its confusing organizational form and semidemocratic structure will likely undermine any sense that the broader community is involved in an open decision-making process and voluntarily ceding power to a representative board. Most likely, what little authority ICANN has flows from a complex - and possibly unknowable combination of sources: from Jon Postel, from the U.S. government, from the many constituencies who use the Internet, and from the Internet community as a whole. ${ }^{252}$ However, retention of the semidemocratic form will slow this flow to a trickle, especially as the Internet community continues to become disengaged in the decisionmaking process and literally disenfranchised.

The final, and most controversial, concern related to ICANN's semidemocratic structure is that the Internet community never becomes actively involved in the management of the DNS or other functions that ICANN is intended to address. ${ }^{253}$ The heart of the experiment in using the Internet to create legitimacy through openness and representation is the belief that the Internet community as a whole can best determine how to govern themselves. However, in a semidemocratic structure, where individuals are able to participate in the process but never have decision-making authority or take on real responsibility, the Internet community never comes into its own. As one political theorist puts it, "In the domain of public affairs people could never outgrow their childhood." ${ }^{254}$ ICANN has entered its awkward teenage phase a few years early and is in danger of never reaching the full potential of its adulthood.

On the simplest level, this problem represents a lost opportunity to develop, through ICANN, a model to govern the technical architecture of the Internet. While ICANN is not intended to foster global democracy, its founding principles state explicitly that it is intended to achieve a representative system for coordinating the Internet. The stronger form of the argument is that ICANN is meant to demonstrate, as the IETF did before it, that Internet users are capable of governing themselves. If individual members of the Internet community never take on responsibility for ICANN's work, political scientists predict the community will never come to participate in a responsible manner. ICANN's authority figures would continue to bear full responsibility

252. Herbert Burkert, in a short piece about ICANN and legitimacy, posits that its authority is grounded in three sources: the At-Large Membership, interest groups, and national governments. See Herbert Burkert, Responsibility for ICANN — Stability and Legitimacy (Feb. 4, 2001), at http://www.atlargestudy.org/Zurich-E.pdf .

253. In some senses, this "lost opportunity" point is Professor Froomkin's main thrust in Habermas. See Froomkin, supra note 33. ICANN, given its special claim to legitimacy and its global reach, ought to, but does not, pass Habermas's demanding test.

254. ROBERT A. DAHL, DEMOCRACY AND ITS CRITICS 105 (1989); see also GALKIN, supra note 242 . 
for the organization's activities without the benefit of an engaged global community of Internet users. This loss to ICANN would mean it would lose the active participation of people who might volunteer their time or present useful ideas. Such active partic ipation might help develop the legitimacy of authority that ICANN has lacked since its founding. In short, ICANN might never become the truly representative body that its founding principles suggest it ought to be.

This lost opportunity might also have other ramifications across cyberspace. To date, the Internet has been effectively self-regulated in particular areas that traditional jurisdictions fail to reach. ${ }^{255}$ In Barlow's c yberspace, for instance, Internet users self-govern to the extent that governance is necessary at all. ${ }^{256}$ Although Barlow's corners of the Internet eroding, sovereign governments have yet to reach many unregulated online communities, such as Usenet groups, discussion forums, and the "darknet." ${ }^{, 257}$ If the Internet community does not assume the responsibility it was intended to have in ICANN, it may never mature into a vibrant self-governing entity.

Worse than preventing the Internet community from coming into its own, the ICANN semidemocratic structure may result in mass frustration and a "checking out" on the part of rational Internet community members. Rational choice theory suggests that voters make a calculation when they decide whether or not to vote. ${ }^{258}$ As André Blais notes, "[The voter] decides to vote if, in her view, the benefits of voting are greater than the costs; if, on the contrary, the costs are greater than the benefits, she decides not to vote. ${ }^{259}$ Semidemocracies suffer a rational choice theory problem. In the first election, participants may not recognize that the benefits of voting are outweighed by their time and effort spent to vote. However, in the event that their elected representatives fail to represent them well because of flaws in the election process, those same participants becoming increasingly unlikely to vote in subsequent elections.

Despite its shortcomings, rational choice theory has relevance to the effect of ICANN's semidemocratic structure on the Internet community. Rational choice theory is far from a perfect explanation of voting choice decisions. It fails to address the "paradox of voting": even when participants could not rationally believe that their vote matters, large numbers of people still turn up at the polls. ${ }^{260}$ Nonethe-

255. For instance, consider standards-setting bodies like the IEEE and the W3C.

256. See supra note 104 and accompanying text.

257. See Peter Biddle et al., The Darknet and the Future of Content DISTRIBUTION, at http://crypto.stanford.edu/DRM2002/darknet5.doc (last visited Feb. 24, 2004).

258. See ANDRÉ Blais, To Vote OR NOt to Vote: THE Merits AND Limits of RATIONAL CHOICETHEORY 1 (2000).

259. Id.

260. Id. at 2. 
less, elements of rational choice theory have merit. Rational voters use some calculus in determining whether to participate in an election. For many voters, one factor in that calculus is whether or not their vote may have an impact now or in the future. In ICANN's case, to the extent that voters believe that their vote could not possibly have an impact on the outcome of DNS coordination, rational actors will decide not to vote in future Internet-based elections.

Several outcomes follow from rational apathy besetting ICANN's elections and other forms of participation. ICANN may suffer if the "rational" Internet users do not vote but the "irrational" do vote. If only the irrational voters vote, they will elect representatives from the fringes of the Internet community. Participation of fringe candidates on ICANN's board may result in transaction costs without any offsetting benefits to the organization from their work. Another potential side effect of mass frustration is factionalization, which was one of the key fears of the drafters of the U.S. Constitution. ${ }^{261}$ Faction ensues because of the fractionalization of the voting populace, which is artificially limited by rational voters deciding not to vote. A third possible outcome is that when rational voters stop participating, ICANN's board and managers lose touch with large segments of the Internet community and therefore have no chance of acting in a representative fashion. By keeping the lines of communication open between the community and ICANN, those who care about ICANN will spend less time complaining and more time working together to solve common problems. Just as important, these placative politics result in a disengaged politics, the opposite of an energized politics. An energized politics is desirable because it engages a high-level of civic involvement and serves as an antidote to impasse in tough situations. ${ }^{262} \mathrm{Fi}-$ nally, the less impact that voting has on decision making and the fewer rational voters who participate, the less efficiently the organization can incorporate public input.

The lost opportunity argument against a semidemocratic ICANN is vulnerable to attack because ICANN's disenfranchisement of the broader Internet community is not, in actuality, a lost opportunity. The average Internet user has limited technical knowledge compared to the average ICANN staff person or board member. Even in the aggregate, the Internet community is unlikely to contribute to the process of fulfilling ICANN's mandate. ICANN's staff and board might make bet-

261. See generally The Federalist No. 10 (James Madison) (containing perhaps the most famous articulation of the fear of faction and its possible causes and effects; Madison, however, notes that pure democracy presents the greatest risk of faction).

262 See UNGER, supra note 217, at 263-77 (describing the impact and importance of a high-energy politics). A high-energy politics is one of the original promises of the Internet, according to many observers from the political sciences. See James F. Moore, The Second Superpower Rears Its Beautiful Head, at http://cyber.law.harvard.edu/people/jmoore/ secondsuperpower.pdf (Mar. 31, 2003). 
ter decisions without the distraction of extensive commentary from an astonishingly fragmented user community. Moreover, ICANN is not intended to foster global democracy; its job is to perform a technical coordination and care-taking function. ${ }^{263}$

This critique, however, incorporates at least three presumptions that may not be accurate. First, the critique presumes that those appointed into positions of responsibility will be more talented and more capable of carrying out ICANN's mandate than other members of the Internet community. Second, this critique presumes that appointed members would be both willing and able to understand and represent the broader community in the decision-making process absent any apparent controls to keep them in check. Third, this critique presumes that ICANN's role is purely technical and that ICANN's exercise of authority lacks any meaningful social impact. In addition, this critique of the lost opportunity argument fails to consider that ICANN relies heavily on volunteers. If more-capable volunteers opt out based on their calculus that they do not wield meaningful influence, ICANN will suffer because it will only be able to draw upon less-capable volunteers. Finally, in the semidemocratic structure, ICANN's leaders will still have to address nput from the broader community, but unlike a situation of energized politics, that input will include fewer good ideas and creative solutions.

The lost opportunity problem is, however, ultimately unsatisfying as a critique of ICANN, because it assumes that ICANN is the body to prove that the Internet can govern itself. True, the broad principles set forth in its founding documents give rise to the plausible reading that ICANN bears a responsibility for proving the Internet's ability to create more responsive, democratically governed, global institutions. Several years into the experiment, however, it is clear that ICANN is not the right institution to prove such a point. ICANN, throughout its history, has tried to do too much; consequently, it has been unable to do anything as well as it might have done. As intriguing as the experiment of creating democratic governance via the Internet is,

263. Joe Sims, ICANN's outside counsel, wrote in a posting to the ICANN Web site:

The more direct influence that the general population - even the general user population - is given over the actual decision-making processes of ICANN, the more risk to the prime objective of continued stability, and the more pressure there will be for the only realistic alternative: control of ICANN by some form of multi-national body, where we would likely get stability all right, but combined with more control[,] less freedom[,] and less innovation. The fact that the global community of national governments has so far allowed and even encouraged this private sector approach is quite remarkable, and owes great credit to the United States government for its leadership in this regard, but this forebearance [sic] is neither pre-ordained nor guaranteed.

Posting of Joe Sims, supra note 237. 
ICANN should relinquish the experiment to an organization more capable of achieving success. Once free from the burden, ICANN should be restructured to the form most effective at achieving its core mission: the management of the DNS.

\section{CONCLUSION}

"[G]LOBAL AND NATIONAL P OLITICS, AND THE HONEST SEARCH FOR THE BROADEST POSSIBLE CONSENSUS O F ALL INTERESTED STA KEHOLDERS, HAVE COMBINED TO PRODUCE

AN ICANN DRAFTED BY COMMITTEE. AS COULD BE EXPECTED, THE RESULT IS NOT A PERFECT INSTRUMENT FOR ANYTHING, INCLUDING ITS PRIME OBJECTIVE [TO MAINTAIN THE STABILITY OF THEDNS].” JOE SIMS, ESQ. (OUTSIDE COUNSEL TOICANN; PARTNER, JONES, DAY $)^{264}$

The best way to manage the DNS, and the best way to prove that the Internet user community can be involved in the decision-making process on issues of global importance, are not one and the same. ${ }^{265}$ These two issues have been conflated in the debate over ICANN's legitimacy of authority. ICANN's failure to create legitimacy through representation and openness means that its structure ought to be reformed to achieve its narrow technical mandate. Regardless of whether ICANN can endure as a technical body, the community as a whole is left with the continuing need to establish a compelling theory for the governance of the technical aspects of the global Internet.

Three key points emerge from this analysis of ICANN's experiment in governance structures. First, with a goal toward selecting the organizational structure most suited to its narrow mandate ICANN must move away from its semidemocratic phase, and continue to pursue substantial structural reform - more substantial than the marginal reforms proposed by ICANN's leadership to date. Second, ICANN should clarify the way in which users can meaningfully involve themselves in the decision-making process to mitigate the risk of demoralization and to get the most out of the input offered by the Internet user community in a manner that is constructive rather than distracting. Such reform should make sure that individuals know the extent to which their participation through various channels will be considered by the decision maker. Third, we need to look past ICANN's troubled

264. Posting of Joe Sims, joe_sims@jonesday.com, to comment-bylaws@icann.org (Oct. 23, 1999) at http://www.icann.org/commentsmail/comment-bylaws/msg00025.html (last visited Feb. 21, 2004).

265. The Berkman Center's "Representation in Cyberspace Study" on behalf of ICANN might in fact render the organization for which I work vulnerable to the accusation that it made precisely this mistake in 1999. See BERKMAN CTR. FOR INTERNET AND SOC'Y, supra note 70. 
story and toward emerging issues of how to govern the technical architecture of the Internet in an increasingly networked world. ${ }^{266}$

\section{A. ICANN Should Pursue Meaningful Structural Reform}

ICANN's structural reform could proceed in several possible ways. Least likely, ICANN could become truly representative and open, either through further empowering "shareholders" within the corporate structure or by adopting a new institutional format. Through either the At-Large Advisory Committee, ${ }^{267}$ Nominating Committee, ${ }^{268}$ or otherwise, ${ }^{269}$ ICANN could give the user community greater voice in the decision-making process, moving the organization closer to the Internet user community, and farther from corporate interests and the U.S. government. The Election of 2000, despite its glitches, suggests that global online elections might be operationally feasible. Presuming increased interest in public participation, the remaining concerns about athentication and security can be overcome with study and refinement. In the same way that a government could move from autocracy to democracy, so too could ICANN change from a corporation with an appointed board to a global organization with a purely elected board (or at least a board whose members represent a specific constituency through the Supporting Organizations). ICANN's charter, by-laws, and founding documents provide no explicit road map to guide such a transition, and the trend suggests movement in precisely the opposite direction. The board would have to readjust ICANN's by-laws in order to morph the organization into a more representative body.

A move by ICANN to a model with greater user involvement including but not limited to becoming a representative democracy would have certain advantages, particularly in terms of establishing greater legitimacy. The structure of ICANN would almost certainly become aligned more directly with the grounding principles of representation and openness. If ICANN could overcome the problem of the legitimacy of authority, the Internet community might well develop into an energized, engaged global force - a development that could have numerous side benefits, both for ICANN and for global society at large. It is at best unclear, however, that the result of a purely democratic structure would be an organization better able to fulfill its

266. See Kleinwaechter, supra note 107, at 1124 (arguing that "[w]e live in a transitional period where the old governance system, rooted in the concept of the sovereign nation-state, is increasingly complemented by an emerging new governance system").

267. See ICANN At-Large Advisory Committee, supra note 21.

268. See ICANN Nominating Committee, supra note 241.

269. See, e.g., CTR. FOR GlOBAL StUdies, ENHANCING LeGITIMACY IN THE INTERNET CORPORATION FOR ASSIGNED NAMES AND NUMBERS 8 (2002), at http://www.markle.org/ news/ICANN_Final_Sept18.pdf. 
core mission: maintaining the stability of the Internet. It is similarly unclear that the constituencies currently represented in ICANN would be fully represented, a concern that may be mitigated by the fact that they could be represented by their individual members. ${ }^{270}$ Also, certain very important issues that ICANN addressed have not attracted substantial public commentary, despite a substantial amount of participation on other issues. ${ }^{271}$ A purely representative democracy is far from a perfect answer, at present, to the question of the best structure for ICANN. In addition, there is no meaningful movement in favor of adopting a more democratic model, making such a reform highly unlikely, even were it desirable.

At the center of the possibilities spectrum - and least appealing of all - ICANN could opt to maintain the awkward status quo, despite continued political opposition to its current structure. ${ }^{272} \mathrm{Mr}$. Lynn's proposed reforms of February 24, 2002, and the reform efforts pursued by the board since that time, though substantial in their own way, would fit in this band of the spectrum. ${ }^{273}$ The NGO and Academic ICANN Study and At-Large Study Committee reports of 2001, though critical of ICANN and urging further involvement of the user community at large, also supported variations of the hybrid status quo. ${ }^{274}$ The perils of the semidemocratic structure are substantial and well-documented. To the extent that ICANN perpetuates a semidemocratic structure, its leaders would be well advised to consider, and seek to avoid, the pitfalls that political scientists and historians predict for semidemocratic institutions. Changes at the margins of ICANN's structure, or even a heightened awareness of the structure's flaws, may mitigate or even prevent certain adverse consequences from coming to pass. The attention paid to ICANN's every move by members of the press, on Internet message boards and newsgroups, in e-mail-based newsletters such as the widely read Politech by $\mathrm{C} \mid \mathrm{Net}$ reporter Declan McCullagh, ${ }^{275}$ and weblogs by the likes of Bret

270. This representation could work in one of two ways. If the corporate Internet interests, for instance, felt under-represented, they could organize their staff, shareholders, and other interested parties to vote in ICANN elections. Similarly, those interests could nominate their own staff to serve on the ICANN board, just as Karl Auerbach of Cisco Systems did during his term.

271. See supra Section III.B.

272. Given the statements of the U.S. Department of Commerce in September 2002 and September 2003 about the need for ICANN to change in order to comply with the terms of the MoU, a scenario with no further reform seems unlikely. See MoU 2002, supra note 5. However, the renewal of the MoU, with its continued emphasis on turning over the job of DNS management to the private sector, suggests that marginal reform within the current corporate structure may yet be likely.

273. LYNN, supra note 131. Mr. Lynn stepped down after a two-year term, so his influt ence over future reforms is virtually nil.

274. See NGO \& ACADEMIC ICANN STUDY, supra note 16.

275. Declan McCullagh, Politech, at http://www.politechbot.com (last visited Feb. 21, 2004). 
Fausett $^{276}$ and Dan Gillmor ${ }^{277}$ — functions as a very important check on ICANN's ability to act in a manner adverse to the interests of the global Internet community. This method of public awareness may be yet more effective if Internet users recognize the shortcomings of ICANN's structure, such as the danger of capture, and adjust their monitoring behavior accordingly.

Third, ICANN might move to a purely autocratic model. The existing board of directors might simply appoint new board members or extend their tenure as terms expire, pursuing a "divine right of kings" approach to governance. The At-Large Advisory Committee, Nominating Committee, and the Supporting Organizations could play a purely advisory role. ${ }^{278}$ This approach would avoid some of the problems of semidemocracy, such as the added costs of functionally meaningless elections, and the outside possibility of "irrational" participants voting fringe candidates onto the board. This reversion would not solve ICANN's legitimacy problem, would represent a back-tracking on core founding principles, would not include adequate recourse in the event of capture or bad decision making, and would leave ICANN open to the critique that an opportunity to develop an engaged global Internet community had been squandered completely. However, this autocratic approach might well be the most efficient way to structure ICANN in order to carry out its narrow technical mandate.

ICANN has a fourth option as well, which is to explore a new model for the organization's structure. ${ }^{279}$ One often-mentioned option is to create a new multilateral treaty organization that would draw together all nations with an interest in the Internet DNS into an agreement to establish an ICANN successor organization. ${ }^{280}$ Simi-

276. Bret Fausett, ICANN.blog, at http://icann.blog.us (last visited Feb. 21, 2004).

277. Dan Gillmor, E.Journal: News, Views and the Silicon Valley Diary, at http://web log.siliconvalley.com/column/dangillmor (last visited Feb. 21, 2004).

278. Similarly, the Supporting Organizations could continue to select some board members, though this approach would obviously retain an element of complexity.

279. See, e.g., Elliot Noss ET Al., A NEW APPROACH to ICANN RefORM: THE HEATHROW DECLARATION (Mar. 25, 2002), at http://www.byte.org/heathrow/ heathrow-declaration-v0r0d5-032502.html (discussing reform proposals and new ideas for ICANN's structure); ICANN, Links Concerning ICANN's 2002 Evolution and Reform Process, at http://www.icann.org/committees/evol-reform/links.htm (last visited Feb. 7, 2004) (providing an updated listing of proposals and ideas).

280. On this topic, Professor Zittrain has written,

[a]n international treaty organization is one possible way that governments could come to agreement on how this particular aspect of the Internet should be run. My personal guess is that this would be the likely outcome if ICANN were to fail. It's not clear to me that such an organization would make policies any more in touch with the Internet at large than a well-function[ing] ICANN can. More important, as the historical context suggests, the power of the root derives from the fact that a critical mass of system administrators and "mirror" root zone server operators choose to follow it. 
larly, ICANN could be folded into an existing treaty organization under the auspices of United Nations, such as the World Intellectual Property Organization. ${ }^{281}$ An attractive variant of these proposals would be for such a treaty organization's board to vest authority in a group of professional managers, and provide them with a fixed series of criteria for performance, while retaining the possibility of periodic removal. ${ }^{282}$

A multilateral treaty-based organization could help ICANN to establish its legitimacy insofar as it would no longer be a California corporation operating under agreement with the U.S. Department of Commerce. However, a treaty-organization structure could bring with it additional bureaucracy, attendant transaction costs, and potentially some of the legitimacy of authority problems of the semidemocratic structure. ${ }^{283}$ The treaty-organization model would give up on the notion of the private sector leading, which might or might not be a large sacrifice. More worrisome, this approach would remove the decisionmaking process further from the Internet user, unless creative mechanisms were developed to incorporate feedback from the Internet user community and NGOs. Such an outcome would fail to achieve the goal of creating "more pluralistic models for Internet governance," as Zoë Baird, President of the Markle Foundation, has forcefully agued. ${ }^{284}$ In the event that ICANN were to shift to a treaty-based model or to a more traditional structure with cleaner lines and crisper decision-making processes, the experimental nature of ICANN would surely be lost. However, the result of such a governance structure might well, on balance, be best for the Internet and its users.

M. Stuart Lynn was right: "ICANN needs reform: deep, meaningful, structural reform, based on a clearheaded understanding of the successes and failures of [ICANN's history to date]. ${ }^{, 285}$ The U.S. Department of Commerce echoed this sentiment, stating that "finalizing the future shape of ICANN is an urgent priority." 286 However, incremental change, such as the change proposed by President Lynn and others after him, offers only the prospect of incremental improvement

Zittrain, supra note 45.

281. See World Intellectual Prop. Org., About WIPO, at http://www.wipo.org/aboutwipo/en/overview.html (last visited Feb. 21, 2004).

282. The description of such a model is a fitting subject for another paper. The advantages of a system of this sort include grounding ICANN in an agreement that includes multiple states rather than a single state. Another advantage could be a more direct alignment of the interests of the Internet user community with the managers and board, while retaining some element of private sector involvement, as sought by the founders.

283. Those who administer related systems, such as the telephone number system, for the ITU, would almost certainly disagree with this critique of the treaty-organization model, citing their own relative efficiency.

284. Zoë Baird, Governing the Internet: Engaging Government, Business, and Nonprofits, FOREIGN AFFAIRS, Nov./Dec. 2002, at 15.

285. LYNN, supra note 131.

286. Statement Regarding MoU, supra note 5. 
to an organizational structure in need of true overhaul. Joe Sims, too, is surely correct: not only was ICANN drafted by committee, but this problem plays out in Technicolor in ICANN's structure and in the problems raised by ICANN's apparent lack of clarity around the issues of representation and openness. ${ }^{287}$ The relentless focus on process, from the moment ICANN was founded, rather than on the substance of its mission, has been and continues to be counterproductive. Sooner rather than later, ICANN should break with its history and seek an organizational structure that is at once true to its principles and capable of enabling its managers to achieve their core mission: preserving the stability of the Internet. And sooner rather than later, the question of what to do about ICANN's crisis ought to be separated from both the effort to build stronger democratic institutions using Internet technologies, ${ }^{288}$ and the continued search for a compelling mode of governance for the technical architecture of the Internet.

\section{B. ICANN Should Clarify Its Governing Principles and Ensure that Users Know How Best to Participate and How, If at All, They Will Be Heard}

ICANN has done a laudable job of enabling the global Internet user community to offer input, but has done a poor job of making clear how the decision-making process works and the precise role of user input in that process. The process has shifted constantly and all but the most attentive followers lose track of the latest changes. If the proper way for users to have a meaningful voice in the process is through the Supporting Organizations, that guidance should be made clear to users. If commentary to the public forums is unlikely to play a role in decision making, users should be made completely aware of this fact. By continuing to mislead users about the extent to which the process is open, and the extent to which user input affects decision making, ICANN risks further demoralization of the global Internet community. Even if the answer is that users ought to find other ways to participate in the technical governance of the Internet, such an answer would be better than a regime of placative politics with lip service toward, but no meaningful consideration of, user input. Openness, in the sense of clarity of process, should be a critical starting point of any structural reform.

287. Diane Cabell, Esq., a key author of the Berkman Center for Internet and Society at Harvard Law School's report on representation at ICANN, appropriately asks whether this problem is a necessary result of the attempt to structure representation based on hard-todefine "interests," rather than on "individuals" or other more clearly defined entities.

288. See Froomkin, supra note 33, at 751-57. 
ICANN's structure must ultimately reflect the principles and goals that the global Internet community sets forth for it, or else reset expectations for what ICANN is meant to accomplish. ${ }^{289}$ If ICANN is intended to be a dynamic, experimental, energizing organization that fulfills a critical function for a global public resource, its organizational structure should be altered to reflect those intentions. If ICANN is intended to be a simple not-for-profit focused on a narrow mandate - unencumbered by higher-minded principles and goals - then the organizational structure should be simplified to reflect those intentions. The current hybrid structure seems to please virtually no one. This outcome, Joe Sims notes, may be the necessary result of compromise. ${ }^{290}$ Most troubling, though, the current hybrid structure, even absent the five elected directors, serves to frustrate ICANN's ability to live up to its founding principles, obscures the user community's ability to understand how best to participate in the decision-making process, and risks continued alienation of the broad Internet community. ICANN is fascinating as an experiment in ways to achieve the goal of representation and input of the global community of Internet users, but it must at some point settle into an organizational structure with a predictable, sustainable process of governance on which stakeholders can rely for the purposes of determining a rational investment of time and resources.

\section{We Ought to Turn Our Focus Away from ICANN and Toward Developing a Compelling Model for Governance of the Technical Architecture of the Internet}

Our attention should turn away from how ICANN is managed and toward the broader issue of how we govern those elements of the technical architecture of the Internet that have greater interest to the majority of Internet users. ${ }^{291}$ ICANN was the wrong test case for proving that the Internet could foster global democracy. We should look to the ICANN experiment in global democratic governance for lessons to guide future atempts to use the Internet to foster more

289. The Evolution and Reform Committee's Proposal, as ratified by the ICANN board in June of 2002, suggests a means of reform but little clarity in terms of resetting expect ations and restructuring the organization. See BLUEPRINT FOR REFORM, supra note 172.

290. Sims, supra note 264.

291. It is here that I part ways with the public-spirited arguments of Common Cause and others that representation through direct voting of board members is essential to ICANN's success. I agree with many of the principles stated in Section 1.1 of the Common Cause Executive Summary of the NGO and Academic ICANN Study Report, for instance, but not with the recommendation in Section 1.4 that "a voice for members directly within the decision-making Board" is a good idea for ICANN as a semidemocracy. NGO \& ACADEMIC ICANN STUDY, supra note 16. 
open, representative, and legitimate institutions that draw upon civil society and the Internet community at large. ${ }^{292}$

A new generation of global organizations, charged with mandates covering compelling subject matter and making use of Internet technologies, might yet emerge. ${ }^{293}$ ICANN, doomed by its own tortured history and limited by the inaccessibility of its subject matter, as suggested throughout this analysis, is highly unlikely to become a model of this sort and should no longer be looked to as a beacon, unless it undergoes truly meaningful reform.

To the extent that governments, standards bodies, corporations, or new genres of organizations seek to use the Internet to strengthen global public involvement in their decision making, the participants' involvement clearly should be meaningful, not placative, and users should be able to understand how and to what extent their input is considered. ${ }^{294}$ The failure of the ICANN experiment bears with it a threat: that the Internet cannot and will not live up to its promise to invigorate democracies and to achieve broad representation within organizations. That message is not the right message to take from the ICANN story, but continued failures of this sort would threaten to turn this mistaken belief into a self-fulfilling prophecy.

The global Internet community still faces the hard questions that faced us in 1998 as ICANN came into being: who governs the Internet and how? Can, and should, Internet users govern themselves? What is the role of traditional sovereigns and of powerful market players? If

292. Professor Froomkin assesses some of the lessons learned from ICANN but carries this particular ball only a short distance. See Froomkin, supra note 33 at 852-55.

293. A new model could also be based on collaboration among existing organizations, such as the ITU and ICANN. See Houlin Zhao, ITU-T and ICANN Reform (Apr. 17, 2002), at http://www.itu.int/ITU-T/tsb-director/itut-icann/ICANNreform.html (comments by the Director of the ITU's Telecommunications Standardization Bureau on this issue).

294. There are a series of arguments that might run counter to this suggestion that participation must be meaningful and effective in order to be advisable. Professor Frank Michelman argues, quite convincingly, that there may be fundamental reasons why we can never perfectly translate the ideal of deliberative democracy into practical effect, even in the most wonderfully conceived constitutional democracy. Michelman, supra note 111, at 150. Professor Michelman is almost certainly right. If we doubt that we ever can achieve the ideal in any event, but believe that there is value in making the effort, then, one argument might run, we may as well try wherever we can. In the ICANN scenario, this extension of the Michelman argument does not apply precisely. First, ICANN is not a state and certainly not a constitutional democracy, so the parallel to his argument is inexact on those grounds. Second, part of the problem with the ICANN structure historically has been the rhetoric and the appearance of deliberative democracy without much of a reality behind it. The structure allows for almost no incentive on the part of board members to vote for positions that have been reached through deliberative means or for decisions that plausibly stand for the position of the Internet community at large, other than a desire to do what those board members think is right. The argument in this paper is not that the public should have no voice in the ICANN decision-making process, but rather that the public should not be given only the semblance of a voice which is in reality just background noise. Such a semblance of a voice is worse, in effect, than establishing at the outset that the public has no formal role in the decision-making process. It is precisely for this reason that public participation in ICANN has foundered, rather than expanded along with the expansion of the namespace. 
the private sector is still to lead, the private sector must learn to partner effectively with governments and civil society and to lead in a manner that guarantees meaningful public participation. Together, these parties should seek to develop new, open, and transparent governance models. Internet technologies still hold promise in terms of making new models possible and effective, though we ought to learn from the ways in which ICANN's use of methods such as simple bulletin boards, email listservs, and direct election of board members has come up short. The failure of ICANN to live up to its founding principles calls renewed attention to the need for experimentation in using the Internet to foster stronger democratic institutions. ICANN needs to reboot, to establish a new set of principles for its operation, and to develop a structure from the ground up that enables it to carry out its narrow technical mandate. While it ought to be inclusive of the user community, ICANN should not be organized to prove a point about democracy on the Internet; as an organization that manages a technical function, and does not set standards or do much that interests or engages a broad swath of Internet users, ICANN is ill-suited to that end. Those who care about democracy and technology should shift their attention away from ICANN, which is almost certainly now beyond repair, and toward the many greener fields in cyberspace. 